\title{
DEGRADACIÓN DE MICROCUENCAS DE GRAN VALOR GEOBOTÁNICO EN LA ZONA COSTERA MEDITERRÁNEA DE CHILE. ANTECEDENTES PARA RESTAURACIÓN ECOLÓGICA
}

\author{
Víctor Quintanilla Pérez ${ }^{1}$ y Mauricio Morales Constanzo² \\ 1 Dpto. de Ingeniería Geográfica. Universidad de Santiago de Chile. \\ 2 Geógrafo - Universidad de Chile \\ victor.quintanilla@usach.cl
}

\begin{abstract}
Resumen: Se presenta un estudio que valora las comunidades florísticas existentes en dos microcuencas costeras desde un punto de vista biogeográfico: Quebrada de San Jerónimo y Quebrada de Córdova, considerando además su distribución espacial y las relaciones que se establecen en los diferentes ambientes naturales de estos microrelieves húmedos, que bajan de lomajes costeros de la zona mediterránea de Chile central. Básicamente la existencia de microclimas húmedos con constantes nieblas, favorecen el desarrollo de especies del bosque esclerófilo húmedo, destacándose en la microcuenca de Córdova, la presencia de especies propias de las formaciones vegetales del sur de Chile, con tres especies endémicas, considerando además que aquí habita un bosque relicto de un árbol austral, Aextoxicon punctatum. Sin embargo estas microcuencas están afectadas por fuegos, erosión y perturbaciones antrópicas, por lo cual es urgente llevar a cabo medidas de protección y de restauración ecológica. La degradación es un proceso constante.
\end{abstract}

Palabras clave: esclerófilo, fuegos, degradación, relicto, erosión, restauración.

\begin{abstract}
A study is made of the plant communities that exist in two coastal microbasins, from a biogeographical standpoint: Quebrada San Jerónimo and Quebrada Córdova, considering their spatial distribution and the relations that exist in the different natural environments of these wet microreliefs that drop from coastal slopes of the central Chile's
\end{abstract}

* Recibido: 12-09-11. Aceptado: 5-11-12. 
mediterranean zone. Basically, the existence of wet microclimates with constant fog favors the development of species from wet forests, and it is stressed that in the Córdova microbasin there are species belonging to plant formations of the south of Chile with three endemic plants, and there is also a relict forest of a southern tree, Aextoxicon punctatum. Nevertheless, these microbasins are affected by fire, erosion, and anthropic disturbance, so there is an urgent need to apply recovery and ecological restoration measures. The degradation is a constant process.

Keywords: sclerophyllous, fire, erosion, degradation, relict, restoration.

\section{Introducción}

En la costa central de Chile mediterráneo (33-37 sur) existen de manera discontinua, microcuencas que bajan de los cordones montañosos de la cordillera de la costa. Estas microcuencas, también denominadas "quebradas", presentan una vegetación con afinidades florísticas con los bosques húmedos del sur de Chile, producto de migraciones de procedencia austral ocurridas durante las glaciaciones pleistocénicas (Villagrán et al., 1980; Villagrán et al., 2003).

Estas agrupaciones boscosas de áreas litorales reciben el impacto antrópico de la gran urbanización y concentración de población que posee actualmente la zona mediterránea de Chile. Es aquí precisamente donde se genera la mayor cantidad de incendios vegetales durante el prolongado y seco periodo estival, lo que ha tenido como consecuencia la modificación de la composición original de especies, junto con alterar las interacciones ecológicas y disminuir los recursos maderables, afectando de igual modo el potencial de desarrollo de las comunidades locales (Sanhueza, 2001).

En este estudio se presenta la situación actual de los ecosistemas de dos quebradas o microcuencas costeras: Quebrada de San Jerónimo y Quebrada de Córdova. En la primera de éstas, su mayor riqueza florística estaría asociada al curso fluvial inferior, donde se presentan agrupaciones de bosque esclerófilo húmedo; mientras que en la Quebrada de Córdova se sitúan comunidades boscosas mixtas: mediterránea y templada húmeda. Cabe señalar que los sectores de borde de ambas microcuencas, los bosques variarían a un matorral esclerófilo.

De acuerdo a la mayor riqueza botánica que presenta la Quebrada de Córdova, principalmente por condiciones ecológicas más favorables, entre otras; se le otorgará un mayor énfasis dentro del estudio. Por consiguiente, este trabajo tendrá como objetivo conocer la riqueza florística de estos ecosistemas, analizando además los princi- 
pales factores de degradación, con el fin de generar algunos antecedentes para la restauración y conservación.

\section{1. Área de estudio}

Las microcuencas están situadas en la Región de Valparaíso, en la provincia admi-

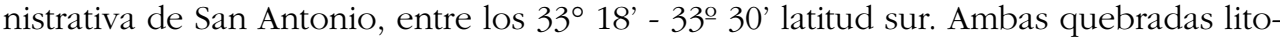
rales se encuentran distantes de unos $10 \mathrm{~km}$ aproximadamente.

La Quebrada de San Jerónimo, conformada por 3 arroyos costeros, se destaca por ser una de las quebradas con mayor extensión en este sector litoral, cercana a los 31 $\mathrm{km}$; sin embargo en el presente estudio solo se comprenden 15-16 km de su extensión. En tanto, más al sur se encuentra la Quebrada de Córdova con alrededor de 6,5 $\mathrm{km}$ de curso fluvial, que se origina de la confluencia de los arroyos de Carvajal y del Rosario (figura 1).

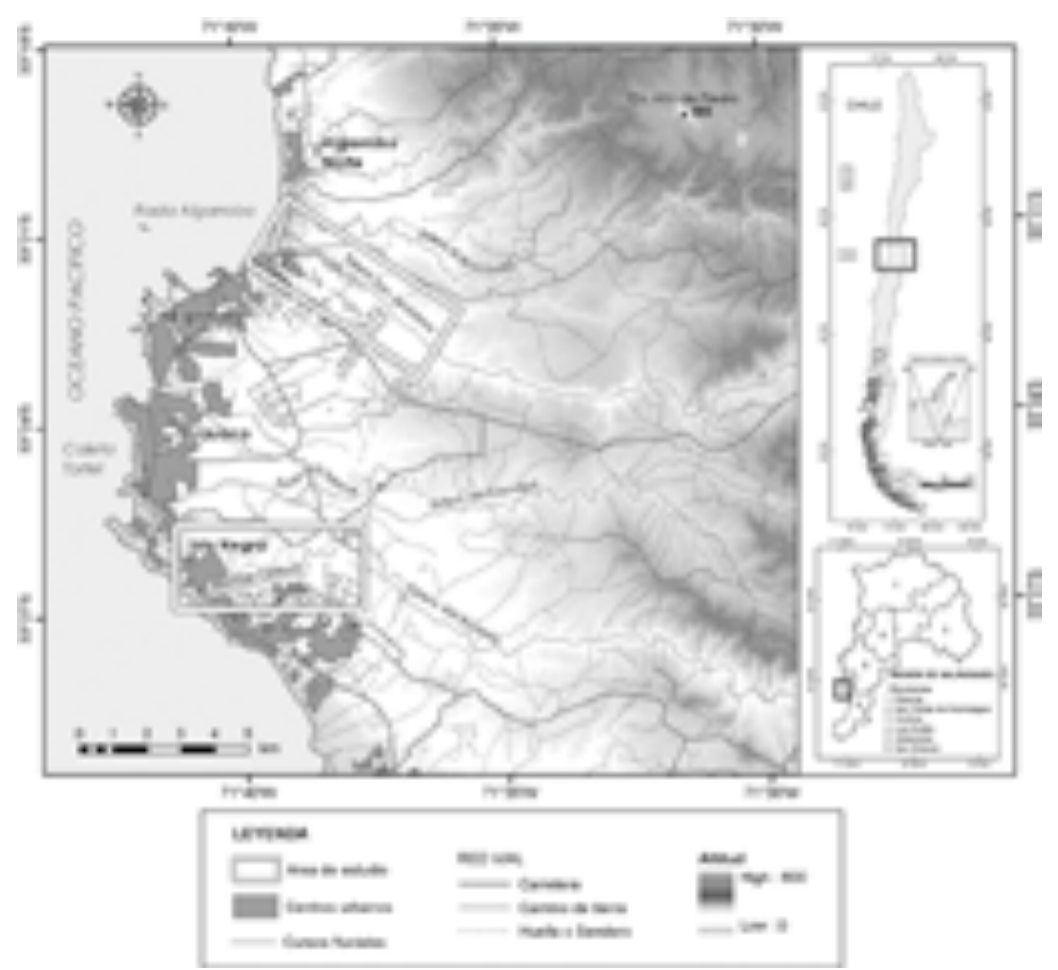

Figura 1. Localización del área de estudio. Quebradas de San Jerónimo y de Córdova. Región de Valparaíso. 
El clima del área de estudio corresponde a un clima templado de tipo mediterráneo cálido, con lluvias invernales y estación seca prolongada. La temperatura media anual es de $16^{\circ} \mathrm{C}$, con precipitaciones que varían entre los 250 y $450 \mathrm{~mm}$ anuales. Este clima se caracteriza además por presentar una alta humedad, con abundante nubosidad y vientos predominantes del sur y suroeste (figura 2).

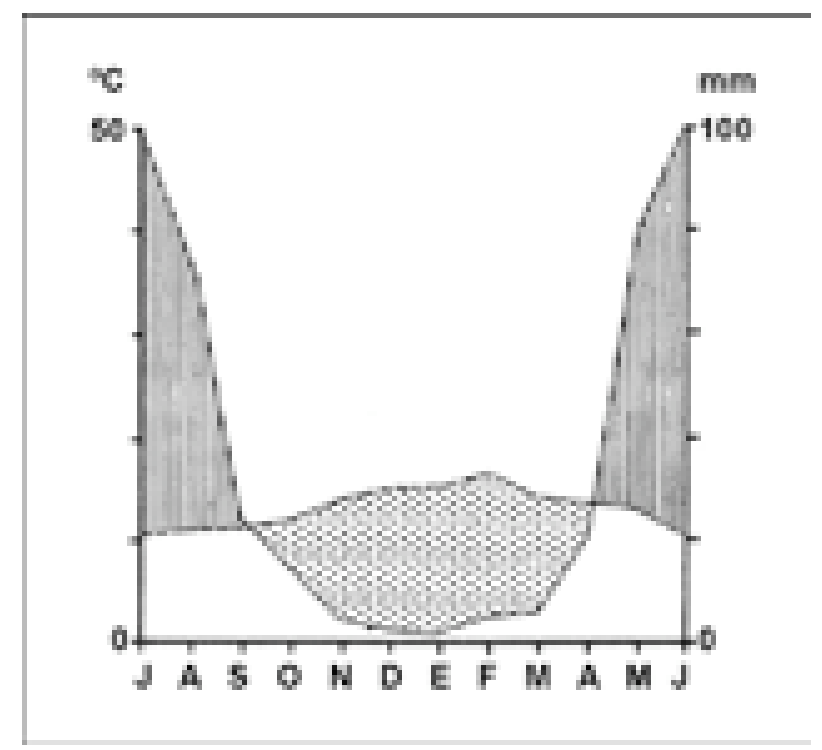

Figura 2. Diagrama ombrotérmico. Estación San Antonio (Hajek y Di Castri, 1975).

Desde el punto de vista geomorfológico, las microcuencas se encuentran situadas en las planicies litorales, conformando disecciones sobre éstas, producto de los solevantamientos generados por la tectónica en el Cuaternario y los depósitos marinos poco consolidados. La base estructural se destaca por su composición granítica en su generalidad y por componentes gnéisicos, existiendo una descomposición en profundidad de la roca que se reduce a arena gruesa o Gruss, denominado localmente como "maicillo" (Araya-Vergara, 2000).

En cuanto al relieve y topografía, la quebrada de San Jerónimo, que posee una orientación nor-poniente, tiene en sus distintos tramos una fisionomía de relieve menos abrupto, con pendientes moderadamente pronunciadas (15 al 25\%). En cambio la Quebrada de Córdova presenta en gran parte de su extensión un mayor desnivel, implicando mayores pendientes de laderas (20 a 35\%), sobre todo en los tramos intermedio y superior. Las altitudes de ambas quebradas varían hasta los 250 m.s.n.m. en los sectores más próximos al océano (figuras 3 y 4). 
En lo que respecta a la descripción y propiedades de los suelos en esta área costera, se conoce que la superficie de las planicies litorales está constituida por "maicillo" como así también por depósitos sedimentarios marinos, y en extensas áreas por arenas eólicas (Castro y Vicuña, 1990).

La principal característica de estos suelos es que son de origen sedimentario, moderadamente profundos, en posición de terraza litoral y de topografía suavemente ondulada. La textura es franco arcillosa y arcillo arenosa, de colores pardo rojizo oscuro y rojo amarillento. Se encuentra sobre un sustrato de gravas redondeadas, donde se distingue la presencia de gravilla de cuarzo y ortosa abundante. En profundidad y en los quiebres de pendiente se observa que esta terraza se encuentra sobre una formación granítica (CIREN, 1997).

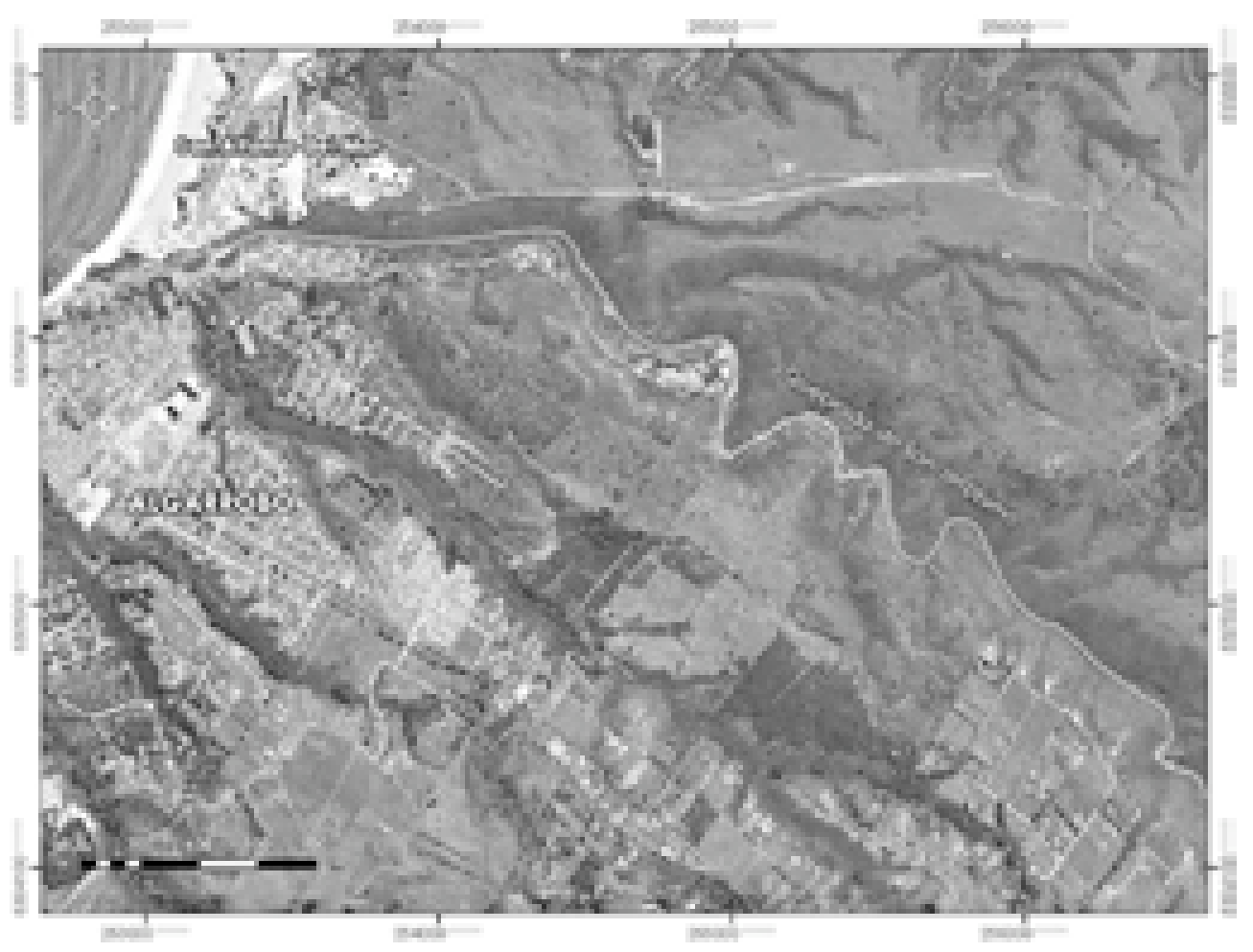

Figura 3. Quebrada de San Jerónimo. Comuna de Algarrobol. 


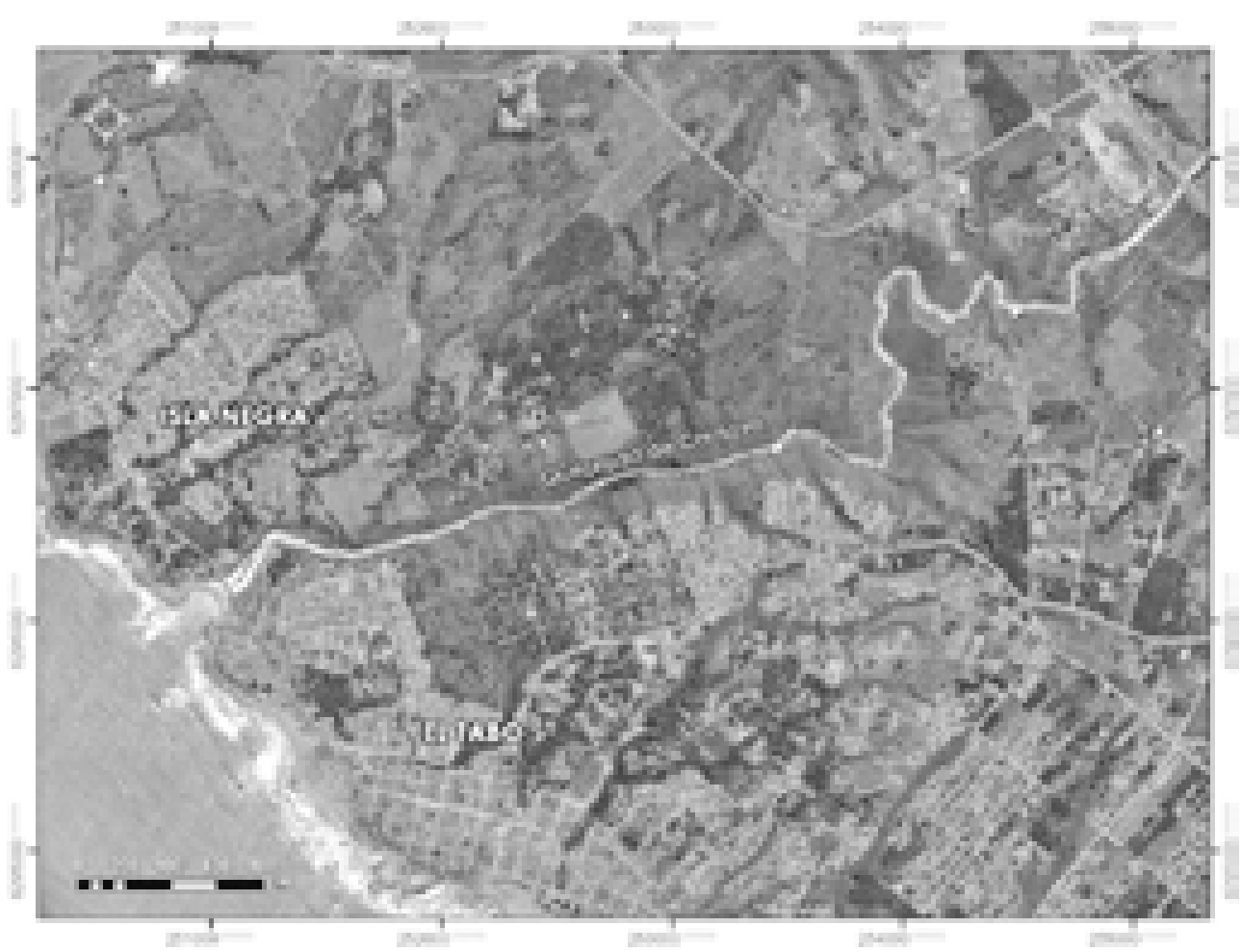

Figura 4. Quebrada de Córdova entre el límite comunal de El Quisco y El Tabo.

\section{Materiales y métodos}

Se realizó en primer lugar una revisión bibliográfica de la vegetación mediterránea (Quintanilla, 1983; Gajardo 1999), y en particular, de los pocos estudios que abordan la fitoecología de las microcuencas costeras seleccionadas (Villagrán et al., 1980; Villagrán et al., 2003).

Para la caracterización de las unidades territoriales (microcuencas y cubiertas vegetales), entre otros aspectos relevantes del paisaje natural y cultural (topografía, hidrografía, centros urbanos, red vial); fue fundamental el uso de diverso material de apoyo como cartografías (1:25.000) e imágenes aéreas (Google Earth), que se complementaron, a su vez, con el uso de Sistemas de Información Geográfica como principal herramienta de análisis espacial. 
Posteriormente se realizaron trabajos de campo entre los meses de Septiembre 2010 y Enero de 2011, y luego entre Marzo y Mayo de 2011, de manera de ajustar las observaciones iniciales de gabinete, identificando la composición florística de las comunidades en diferentes hábitats. Para ello se efectuaron en cada quebrada 12 inventarios florísticos (árboles, arbustos y hierbas), en parcelas de $100 \mathrm{~m}^{2}$ en los sectores de bosque y de $75 \mathrm{~m}^{2}$ para las áreas de matorral esclerófilo; siguiendo la metodología simplificada de uso biogeográfico de Braun-Blanquet (1979). Además se generaron transectas vegetales con el fin de poder caracterizar las variaciones florísticas en los sectores de laderas, según su altitud.

Con respecto a los factores de degradación, se analizaron en primer lugar los registros de los incendios forestales que dispone la Corporación Nacional Forestal de Chile (CONAF), los cuales fueron representados espacialmente dentro una grilla de 100 ha, determinando la densidad de ocurrencia de los incendios. Desfavorablemente solo se pudo contar con información para un periodo restringido, relativamente actual (1998-2006). No obstante éstos representan de igual modo la tendencia de ocurrencia de fuegos para las microcuencas costeras de Chile mediterráneo.

Por otra parte, también se consideró diversa información bibliográfica y estadística referida al clima, principalmente sobre precipitaciones, para generar mayores antecedentes en la estimación de alguna potencialidad de erosión en los suelos.

\section{Resultados y discusión}

\subsection{La vegetación de las microcuencas}

En las costas de Chile mediterráneo, y en parte del sector litoral del semiárido, existen agrupaciones vegetales de distribución discontinua que presentan claras afinidades florísticas con el bosque pluvial del sur de Chile ("bosque valdiviano"), que fueron mencionadas por primera vez en 1884 por el naturalista chileno Rodulfo Philippi, existiendo posteriormente numerosos autores que han intentado explicar dicha similitud exponiendo diversas hipótesis (Villagrán y Armesto, 1980). La más conocida en la literatura interpreta la presencia de las comunidades relictuales en el norte, como el producto de migraciones del bosque del sur de Chile durante las glaciaciones cuaternarias (Looser, 1935; Skottsberg, 1948; Muñoz y Pisano, 1947; Wolffhugel, 1949). Aun no se mencionan los tipos de bosque austral con los cuales existiría mayor relación florística, y tampoco el rol que debería haber desempeñado el bosque de Chile central (mediterráneo), que correspondería, necesariamente, al área de paso de las migraciones procedentes del sur. 
De acuerdo con Villagrán y Armesto (1980), Schmithusen (1956) propuso una hipótesis alternativa para explicar el origen del bosque de Fray Jorge en la costa semiárida, el más septentrional de los relictos (30²9’ S.); enfatizando la importancia del elemento neotropical en la composición florística de dicha comunidad, y sugiriendo una edad terciaria para ella. En 1966 Kumerow, Matte y Schlegel describieron una nueva comunidad en los alrededores de Pichidangui $\left(32^{\circ} 05^{\prime} \mathrm{S}\right.$.), efectuando un análisis florístico comparativo de esta agrupación con los bosques relictos ya descritos en la literatura. En base a estos análisis se concluyó que la hipótesis de Schmithusen sería parcialmente correcta, concordando también con ella Troncoso et al. (1980). Posteriormente, diversos especialistas fueron descubriendo en varias microcuencas nuevas formaciones higrófitas situadas en plena costa mediterránea de Chile.

Entre ellas se destacan las denominadas Quebrada de San Jerónimo y Quebrada de Córdova, sobre las cuales se señalan algunos antecedentes relativos al valor geobotánico que representan.

El tipo de comunidades presentes en la Quebrada o Estero de San Jerónimo, corresponden a la formación del bosque y matorral esclerófilo de Chile mediterráneo, con variantes de hábitats de vegetación higrófila, que han sido afectadas por diversas actividades antrópicas, asociadas principalmente a la ocurrencia de fuegos estivales acaecidos entre los años 1965 y 2006.

Particularmente durante los veranos extensos y secos, el curso de agua de la Quebrada de San Jerónimo tiende a ser intermitente (Galarce y Penrroz, 2010). La mayor parte de las comunidades vegetales adquieren el máximo desarrollo después de las lluvias invernales que se producen entre Mayo y Agosto, con un total anual que alcanza los $400 \mathrm{~mm}$.

En el curso inferior de este estero o arroyo, más precisamente en sus laderas de exposición sur, muy próximas a la desembocadura; predominan especies arbóreas esclerófilas húmedas. De acuerdo a los censos realizados, se identificaron en un primer orden árboles como Cryptocarya alba (Mol.) Looser, Peumus boldus Mol., Azara celastrina D. Don, Schinus latifolius (Gill. ex Lindl.) Engler, Maytenus boaria Mol. También se encontraron dos árboles de los bosques del sur del país como son Myrceugenia exsucca (DC.) Berg, y Aristotelia chilensis (Mol.) Stuntz; identificando además una especie hemiparásita como Tristerix corymbosus (L.) Kuijt; un helecho (Equisetum bogotense Kunth), y una herbácea de talla arbustiva como Gunnera tinctoria (Mol.) Mirb., cuya presencia está asociada a los sectores de mayor humedad.

En laderas del curso medio, particularmente en exposición norte, se encuentran agrupaciones de matorral esclerófilo de carácter mésico, como los árboles y arbustos de Lithraea caustica (Mol.) H. et A., Quillaja saponaria Mol., Kageneckia oblonga R. et P., y arbustos de tipo xérico como por ejemplo Podanthus mitiqui Lindl., Retanilla trinervia (Gillies \& Hook.) Hook. \& Arn., Discaria trinervis (Gill.ex H. et A.) Reiche, 
Colliguaja odorifera Mol., Eupatorium glechnophyllum Less., Puya coerulea Lindl., Colletia ulicina Gill. \& Hook, Mueblenbeckia hastulata (J.E. Sm.) I.M.Johnst., Anisomeria littoralis (P. et E.) Moq., Haplopappus foliosus DC., Margyricarpus pinnatus (Lam.) Kuntze., Acacia caven (Mol.) Mol. También destaca la cactácea Echinopsis chiloensis (Colla) Friedrich \& G.D.Rowley, el arbusto semitrepador Rubus ulmifolius Schott y la enredadera Proustia pyrifolia DC. (figura 5 y tabla 1).

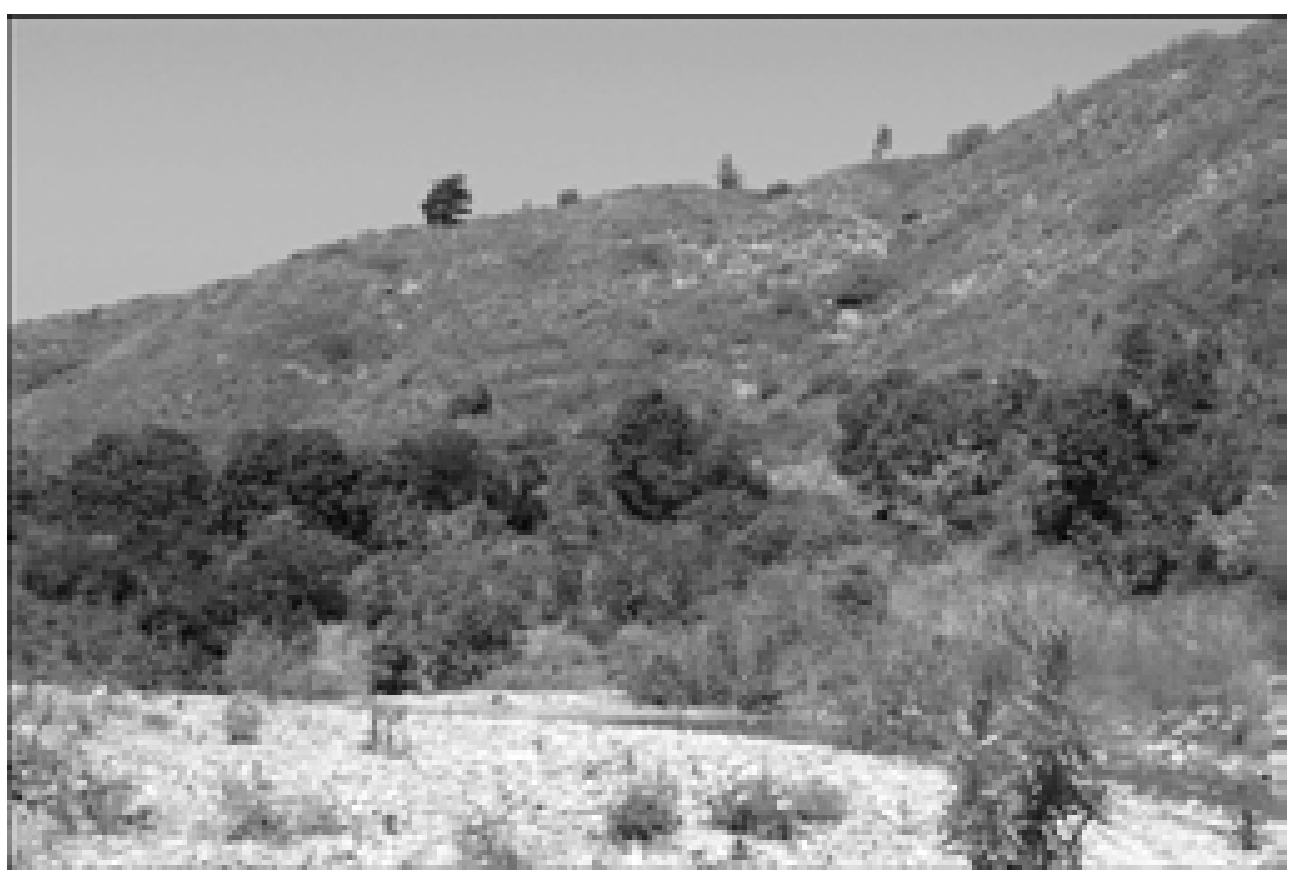

Figura 5. Agrupaciones vegetales de talla arbórea distribuidas en las proximidades del estero San Jerónimo.

Por otra parte, es interesante destacar en ambas laderas la frecuente presencia de la bambúsea Chusquea cumingii Nees., que crece inclusive en el fondo de quebrada, muy próximo al estero. Esta especie es muy común que se desarrolle en los ambientes de vegetación alterada, siendo la primera en colonizar después que el fuego ha eliminado la vegetación leñosa; situación que se ha manifestado notablemente en la quebrada de San Jerónimo, al existir varios sectores con dominio de esta especie en las áreas de los antiguos fuegos forestales. En la microcuenca este tipo de vegetación semixérica predomina en laderas con relativa mayor altitud, fluctuando entre los 25 y 110 m.s.n.m. A su vez la vegetación húmeda de exposición sur se ubica entre los 50 y 180 m.s.n.m. (figura 6). 
Tabla 1. Especies dominantes en diferentes hábitats en la Quebrada o Estero San Jerónimo.

\begin{tabular}{|c|c|}
\hline Hábitats & Especies \\
\hline \multirow{3}{*}{ Mésico } & $\begin{array}{l}\text { ÁRBOLES } \\
\text { Aristotelia chilensis } \\
\text { Azara celastrina } \\
\text { Cryptocarya alba } \\
\text { Maytenus boaria } \\
\text { Myrceugenia exsucca } \\
\text { Peumus boldus } \\
\text { Quillaja saponaria }\end{array}$ \\
\hline & $\begin{array}{l}\text { ARBUSTOS } \\
\text { Chusquea cumingii } \\
\text { Gunnera tinctoria (Herbácea arbustiva) } \\
\text { Lobelia tupa } \\
\text { Mueblenbeckia hastulata } \\
\text { Podanthus mitiqui } \\
\text { Rubus ulmifolius } \\
\text { Solanum nigrans } \\
\text { Sophora macrocarpa }\end{array}$ \\
\hline & $\begin{array}{l}\text { HELECHOS, TREPADORAS Y EPIFITAS } \\
\text { Equisetum bogotense } \\
\text { Lardizabala biternata } \\
\text { Tristerix verticillatus }\end{array}$ \\
\hline \multirow[b]{2}{*}{ Xérico } & $\begin{array}{l}\text { ARBOLES } \\
\text { Citronella mucronata } \\
\text { Kageneckia oblonga } \\
\text { Litbraea caustica } \\
\text { Schinus latifolius }\end{array}$ \\
\hline & $\begin{array}{l}\text { ARBUSTOS } \\
\text { Acacia caven } \\
\text { Baccharis marginalis } \\
\text { Cestrum Parqui } \\
\text { Colletia ulicina } \\
\text { Echinopsis chiloensis } \\
\text { Escallonia Illinita } \\
\text { Puya chilensis } \\
\text { Retanilla trinervia } \\
\text { Rhaphithamnus spinosus } \\
\text { Schinus polygamus } \\
\text { Solanum nigrum } \\
\text { Eryngium paniculatum } \\
\text { Verbascum sp. }\end{array}$ \\
\hline
\end{tabular}

Fuente: Elaboración de los autores en base a los censos fitogeográficos realizados (2010-2011) 
El valor geobotánico del curso medio inferior se establece fundamentalmente por la presencia de árboles esclerófilos húmedos muy maduros y longevos, los cuales alcanzan alturas superiores a los 8 metros, como también de algunos árboles de la selva valdiviana (Myrceugenia exsucca, Aristotelia chilensis). Además se encuentran entre su cortejo florístico helechos (Blechnum hastatum, B. chilense) y algunas trepadoras. Cabe señalar que el efecto de la influencia marina permite que los árboles mantengan en su ramas musgos y líquenes.

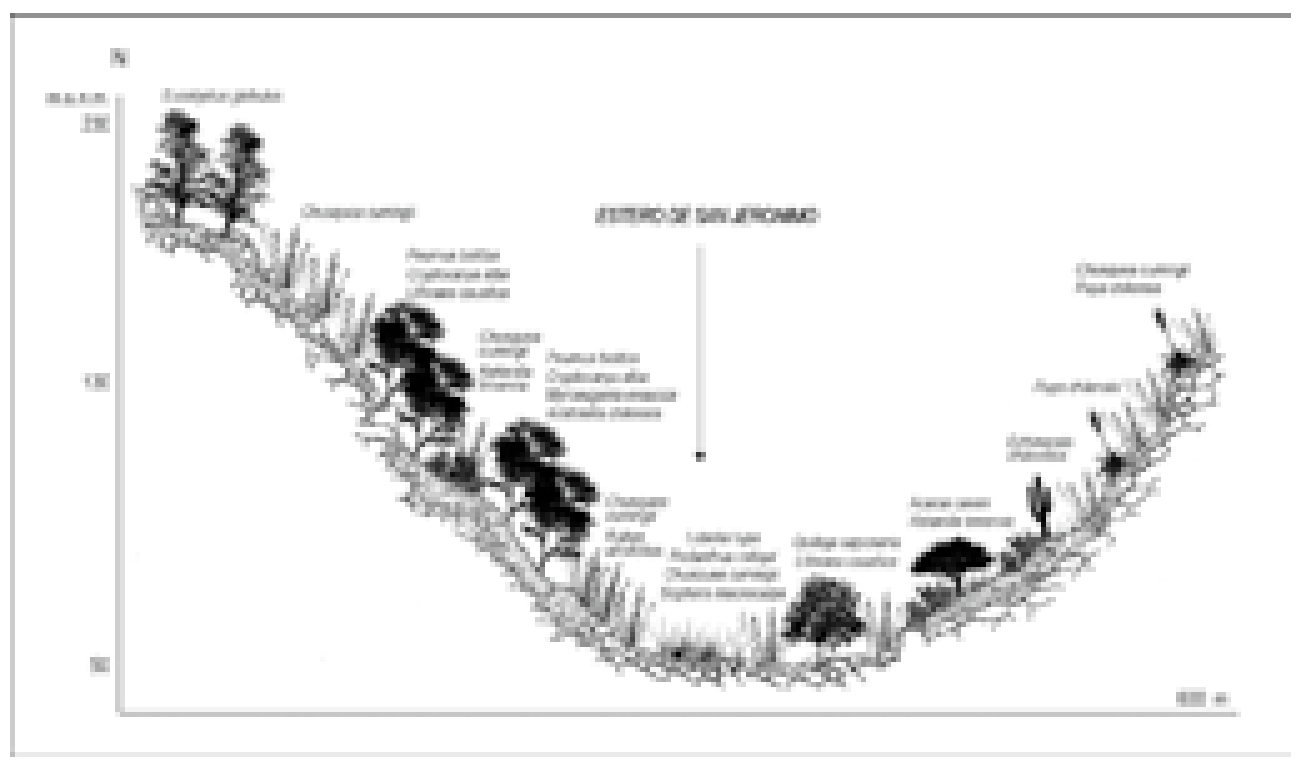

Figura 6. Perfil vegetal tipo de la Quebrada de San Jerónimo.

Con respecto a la Quebrada o Estero de Córdova, presenta una vegetación de bosques discontinuos, que cubren principalmente la ladera de exposición sur, en el curso medio; lugar donde se registran las máximas altitudes de 125-130 m.s.n.m., con pendientes aproximadas sobre el $25 \%$.

Como consecuencia del encajonamiento que posee este sector, junto con la constante influencia de la brisa marina y concentración de abundante niebla entre los meses de Mayo a Septiembre, permiten que esta microcuenca presente una importante humedad. A esto debe agregarse el regular aporte hídrico del curso de agua. Estas condiciones favorecen aquí la estructura, fisionomía y diversidad de la vegetación.

Según Villagrán et al. (1980), en laderas de exposición sur las fluctuaciones de temperatura diurna, tanto del aire como a diferentes profundidades del suelo son 
pequeñas, manteniéndose relativamente constantes. En cambio en las laderas de exposición norte las fluctuaciones de las temperaturas diurnas son más amplias, pudiéndose observar variaciones notorias entre los valores del aire y del suelo a 20 $\mathrm{cm}$. Sin embargo las diferencias de los valores medios de temperatura ambiental son bajos y relativamente constantes $\left(7^{\circ}-12^{\circ} \mathrm{C}\right)$; todo lo contrario con la ladera opuesta, donde los valores de humedad relativa son altos, con un promedio de $65 \%$.

De acuerdo con las formas de crecimiento presentes en los estratos arbóreos y arbustivos de la vegetación, se presenta una clara dominancia de leñosas siempreverdes latifoliadas, con un bajo porcentaje de cobertura relativa (25\%) de las especies deciduas de verano, particularmente bajo los 80 m.s.n.m. Estas se mantienen relativamente constantes en el curso medio del arroyo, no así cuando se encuentran próximas al mar.

Por otra parte, en las áreas de la desembocadura se destaca la importante cobertura de herbáceas y de trepadoras. Es interesante señalar la riqueza de herbáceas primaverales según lo constatado por Villagrán et al. (1980), sobre todo las especies anuales y geófitas que crecen en los espacios abiertos del matorral.

Existen varias especies arbóreas de Mirtáceas como Luma chequen (Mol.) A. Gray, y aquellas de carácter endémico como Myrceugenia exsucca (DC) Berg, Myrceugenia rufa (Colla) Skottsb. ex Kausel, Myrceugenia lanceolata (Jaume) Kausel y Myrceugenia ovata (H. et A.) var. nannophylla (Burret) Landrum; las cuales habitan preferentemente en los sitios bajos, aprovechando la humedad edáfica, varias de ellas con una distribución discontinua y en precario estado de conservación (Villagrán et al., 2003). Otra de las especies arbóreas interesantes de estos ambientes son Escallonia revoluta (R.et P.) Pers y Psoralea glandulosa L. (figura 7).

Entre las especies palustres se encuentran Gunnera tinctoria (Mol.) Mirb. y Equisetum giganteum L.; además de Selliera radicans Cav., Ludwigia peploides (H.B.K.) Raven y los Junquillales de Ciperáceas (Scirpus californicus (C.A. Mey) Steud. y Scirpus cerneus Vahl) y Juncáceas como Juncus balticus Huid, las cuales son muy abundantes. En cuanto a las plantas acuáticas destacan especies de Myriophyllum e Hidrocotyle entre las Angiospermas; Drepanocladus entre las Briófitas, y especies de Algas Verdes (Chara) y Cianobacterias (Nostoc) (Villagrán et al., 2003).

Si bien la agrupación vegetal de mayor riqueza en la microcuenca de Córdova corresponde al bosque esclerófilo húmedo; en el curso medio aparece una importante cobertura de agrupaciones poco intervenidas de Aextoxicon punctatum R. et P. (el olivillo), con elementos arbóreos de hasta 12 metros de altura. Este árbol corresponde a una especie típica del bosque pluvial valdiviano del sur de Chile $\left(38^{\circ}-44^{\circ} \mathrm{S}\right)$; y de acuerdo con su presencia en áreas mediterráneas mésicas, adquiere el carácter de relictual. 


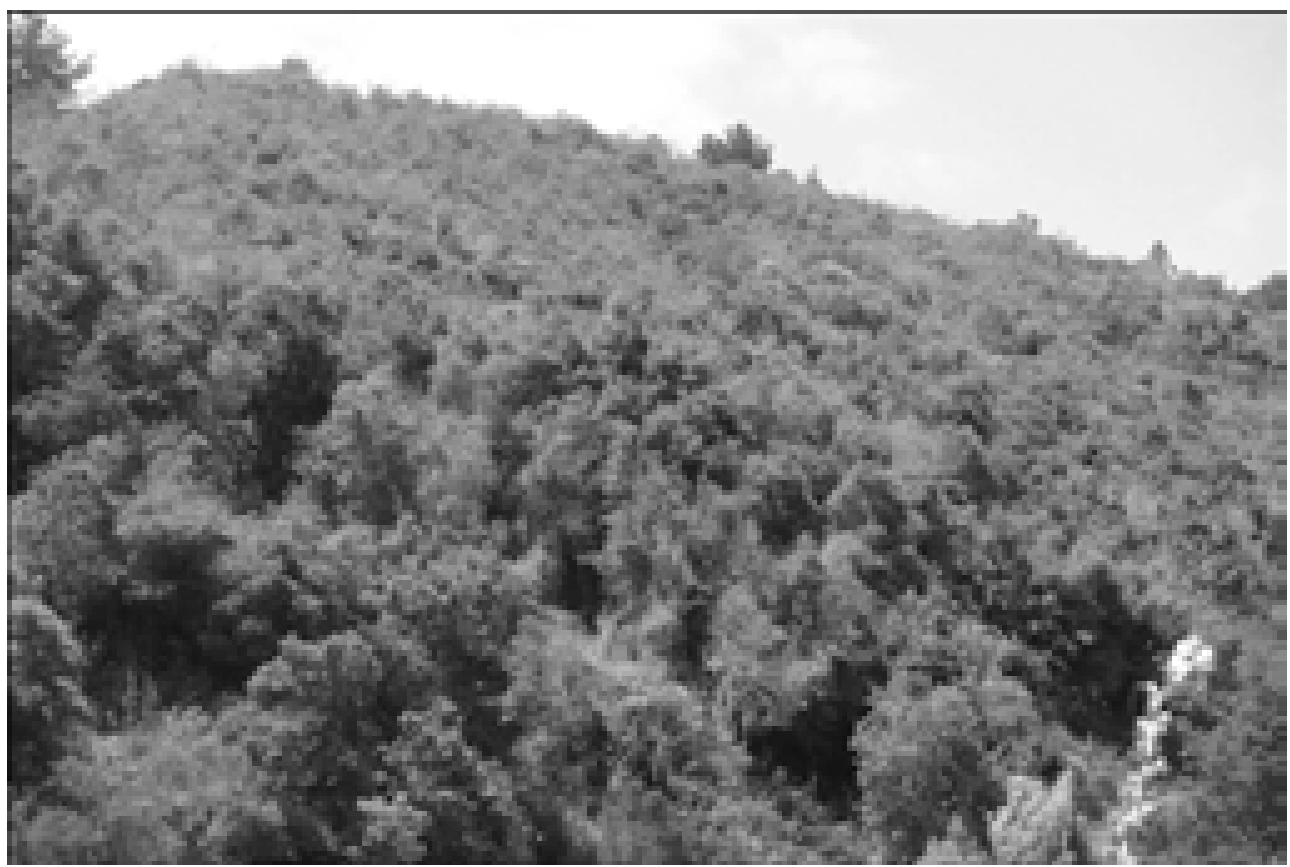

Figura 7. En laderas de exposición sur se destaca la gran diversidad de especies de ambientes más húmedos. Quebrada de Córdova.

Según Villagrán et al. (1980) y Troncoso et al. (1980), la tendencia del bosque de olivillo de ascender altitudinalmente cuando las condiciones microclimáticas le son propicias, permite inferir que, si las condiciones microclimáticas cambiasen de xéricas a mésicas, se produciría un ascenso en altura y un avance hacia el norte de este tipo de vegetación; mientras que en la situación contraria existiría un avance hacia el sur, con un ascenso paulatino hacia los Andes, a medida que las condiciones mésicas se desplazan hacia el oriente.

Debe consignarse que este árbol austral se encuentra también en otras microcuencas costeras, más al norte del área de estudio ( $\left.30^{\circ} 05^{\prime} \mathrm{S}\right)$. Los especialistas en general concuerdan que la actual distribución central norte de Aextoxicon punctatum, es producto de migraciones postglaciales desde Chile austral hacia el norte, bajo condiciones más mésicas que las actuales. En tanto otros autores infieren que habría ocurrido una paulatina distribución desde el norte hacia el sur, encontrándose hoy en día en presencia de una fragmentación de sus hábitats, sobre todo por la presión antrópica (entre ellos los fuegos forestales), que se remonta desde hace mínimo tres siglos en el centro de Chile, lo que habría permitido, a su vez, la expansión del bosque esclerófilo. 
Esta microcuenca por su notorio grado de variedad de especies en ambas laderas, posee una diferenciación fisionómica y florística, debido principalmente al contraste de las condiciones ecológicas, en la cual destaca la constante humedad atmosférica (neblinas) presente en gran parte del año, centrada mayormente en laderas de umbría. En consecuencia, las diferentes exposiciones permiten distinguir diversos tipos de agrupaciones fisionómicas asociadas a un gradiente de aridez, que varía desde la ladera de exposición norte (extremo xérico), hasta aquellas de exposición sur, es decir extremo mésico con variante húmeda (tabla 2).

Tabla 2. Especies dominantes en diferentes hábitats en la Quebrada de Códova.

\begin{tabular}{|l|l|}
\hline Hábitats & Especies \\
\hline \multirow{5}{*}{ Mésico } & ÁRBOLES \\
& Aextoxicon punctatum \\
& Aristotelia chilensis \\
& Cryptocarya alba \\
& Drimys winteri \\
& Lithraea caustica \\
& Myrceugenia correifolia \\
& Myrceugenia obtusa \\
& Myrceugenia rufa \\
& Myrceugenia lanceolata \\
& Myrceugenia ovata \\
& Peumus boldus \\
& Schinus latifolius \\
\cline { 2 - 3 } & ARBUSTOS \\
& Adenopeltis colliguaya \\
& Adiantus chilensis \\
& Azara celastrina \\
& Baccharis concava \\
& Bomarea \\
& Chusquea cumingii \\
& Cissus striata \\
& Citronella mucronata \\
& Diplolepis menziesii \\
Ephedra chilensis \\
Escallonia pulverulenta
\end{tabular}




\begin{tabular}{|c|c|}
\hline Hábitats & Especies \\
\hline \multirow[b]{2}{*}{ Mésico } & $\begin{array}{l}\text { Proustia pyrifolia } \\
\text { Relbunium hypocarpium } \\
\text { Retanilla trinervia } \\
\text { Rubus ulmifolius } \\
\text { Senecio yegua } \\
\text { Sysirinchium junceum } \\
\text { Villaresia mucronata }\end{array}$ \\
\hline & $\begin{array}{l}\text { HIERBAS Y GRAMINEAS } \\
\text { Adiantum poiretii } \\
\text { Alstromeria sp } \\
\text { Alstromeria sp } \\
\text { Dioscorea bryoniaefolia } \\
\text { Dioscorea pedicellata } \\
\text { Francoa sonchifolia } \\
\text { Galium trichocarpum } \\
\text { Gnaphalium purpureum } \\
\text { Hipeastrum bicolor } \\
\text { Mutisia latifolia } \\
\text { Stellaria cuspidata } \\
\text { Tecophilsea violaeflora } \\
\text { Tropaeolum sp. } \\
\text { Uncinia phleoides }\end{array}$ \\
\hline \multirow[t]{2}{*}{ Xérico } & $\begin{array}{l}\text { ÁRBOLES } \\
\text { Cryptocarya alba } \\
\text { Lithraea caustica } \\
\text { Maytenus boaria } \\
\text { Peumus boldus } \\
\text { Schinus latifolius } \\
\text { Schizanthus litoralis }\end{array}$ \\
\hline & $\begin{array}{l}\text { ARBUSTOS } \\
\text { Acacia dealbata } \\
\text { Buddleja globosa } \\
\text { Cardus pynocephalus } \\
\text { Carpobrotus aequilaterus } \\
\text { Cestrum parqui } \\
\text { Chusquea cumingii } \\
\text { Colletia bystrix } \\
\text { Colliguaja odorifera } \\
\text { Echinopsis chiloensis } \\
\text { Foeniculum vulgare } \\
\text { Lobelia excelsa } \\
\text { Lycium chilense } \\
\text { Margyricarpus pinnatus } \\
\text { Oxalis carnosa }\end{array}$ \\
\hline
\end{tabular}




\begin{tabular}{|c|c|}
\hline Hábitats & Especies \\
\hline & $\begin{array}{l}\text { Podanthus mitiqui } \\
\text { Puya chilensis } \\
\text { Retanilla trinervia } \\
\text { Rubus ulmifolius } \\
\text { Sophora macrocarpa }\end{array}$ \\
\hline & $\begin{array}{l}\text { TREPADORAS Y EPIFITAS } \\
\text { Tristerix verticillatus }\end{array}$ \\
\hline & $\begin{array}{l}\text { HERBACEAS } \\
\text { Adiantum chilense } \\
\text { Brassica campestris } \\
\text { Calceolaria corymbosa } \\
\text { Calandrinia grandiflora } \\
\text { Eschscholtzia californica } \\
\text { Haplopappus foliosus } \\
\text { Leucocoryne ixoides } \\
\text { Oxalis articulata } \\
\text { Sphacele salviae } \\
\text { Stellaria cuspidata } \\
\text { Tropaeolum tricolor } \\
\text { Verbascum virgatum }\end{array}$ \\
\hline & $\begin{array}{l}\text { ARBUSTOS } \\
\text { Gunnera tinctoria (Herbácea arbustiva) } \\
\text { HERBACEAS } \\
\text { Juncus balticus } \\
\text { Equisetum bogotense } \\
\text { Scirpus californicus } \\
\text { Sisyrinchium junceum } \\
\text { Trifolium filiforme }\end{array}$ \\
\hline
\end{tabular}

Fuente: Elaboración de los autores en base a los censos fitogeográficos realizados (2010-2011).

Otras de las especies arbóreas higrófitas que se encuentran en esta microcuenca son: Aristotelia chilensis (Mol.) Stunz, Myrceugenia obtusa (DC.) O.Berg, Myrceugenia correifolia (H. Et A.) Berg. y Drimys winteri J.R. et G. Forster (figura 8).

Se debe mencionar además, según Villagrán et al. (2003), la existencia de 3 especies endémicas de Chile que están representadas en la quebrada de Córdova, las cuales figuran como raras a nivel nacional (Muñoz-Schick et al., 1996). Estas son Myrceugenia rufa, Myrceugenia correifolia y Citronella mucronata. 


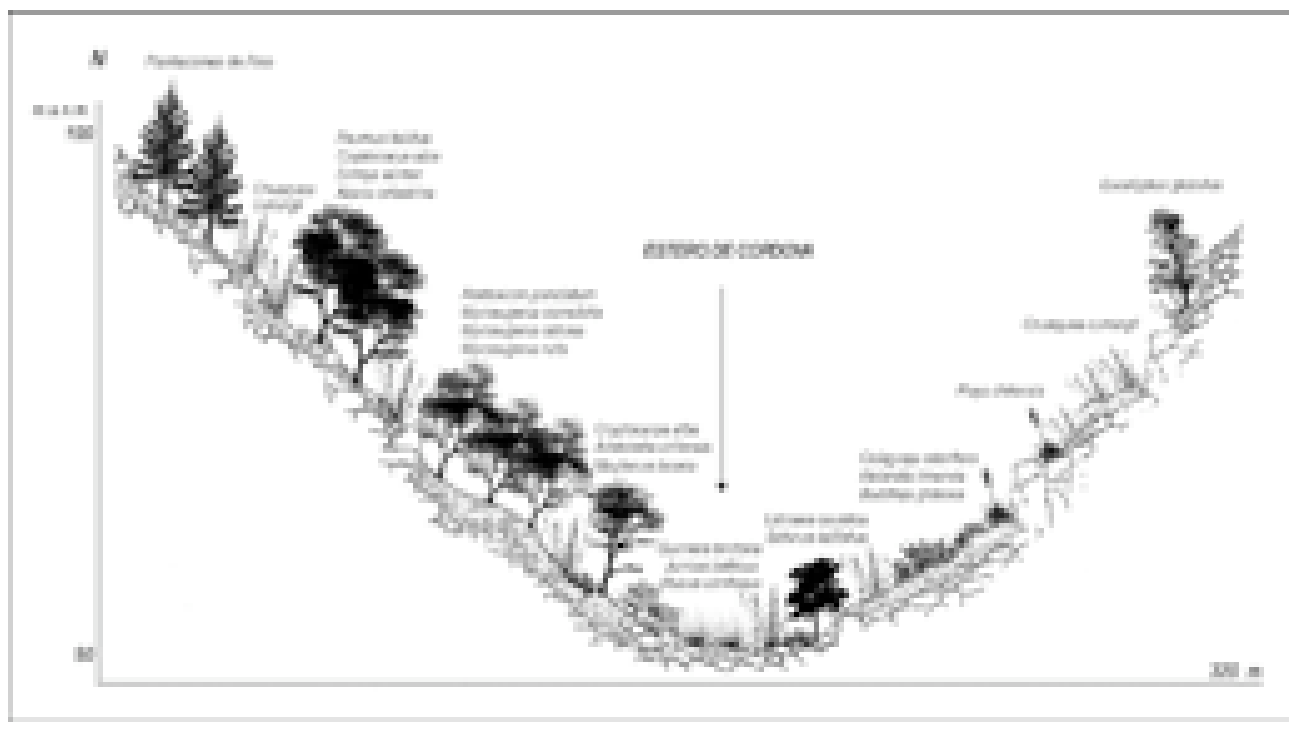

Figura 8. Perfil vegetal tipo de la Quebrada de Córdova.

En cuanto a los árboles esclerófilos asociados a ambientes con mayor humedad, es notable encontrar muy bien desarrollado a Cryptocarya alba, Azara celastrina, Peumus boldus y Maytenus boaria.

\subsection{Degradación en las quebradas costeras}

En las quebradas de San Jerónimo y de Córdova la presión antrópica ha sido importante y diversa, principalmente por la cercanía de los centros urbanos (Algarrobo, El Quisco, Isla Negra y El Tabo), que ha determinado la ocurrencia de distintos tipos de alteraciones. Uno de los mayores impactos y más recurrentes que se han generado en estas quebradas, han sido los incendios vegetales, registrándose varios episodios de incendios en los últimos 30 años (Castillo et al., 2010). Esta situación ha ocasionado gradualmente una degradación de la estructura y fisionomía vegetal, teniendo como consecuencia la perdida de cobertura para la protección de suelos; los cuales también sufren impactos directos del fuego, que afectan sus propiedades edáficas, al quemar su materia orgánica, endureciéndolos y privándolos además de su capacidad de absorber agua.

La franja litoral de Chile Mediterráneo, que comprende principalmente las ciudades de Viña del Mar y Valparaíso, y los balnearios de Algarrobo, El Quisco, Islas 
Negra, El Tabo y Cartagena; corresponde a un área de alta densidad y frecuencia de incendios vegetales, cuyo territorio coincide con la existencia de varios sectores de quebradas que poseen un alto valor en biodiversidad, con presencia de especies higrófitas.

De acuerdo a la tabla 3, se puede observar la frecuencia de los incendios en las comunas de la Provincia de San Antonio, donde estarían situadas las microcuencas en estudio. Entre éstas se destaca la Comuna del Quisco, la cual posee una mayor densidad de fuegos que han afectado 845 hectáreas. En tanto las Comunas de El Tabo y Algarrobo han presentado menos episodios de incendios teniendo, a su vez, una menor densidad de acuerdo a su superficie. No obstante el tamaño medio de los incendios (TMI) es considerable para estas comunas, con eventos de fuegos que pueden afectar sobre las 18 hectáreas.

La importancia de esta información se establece en poder estimar los tiempos de recuperación que tendrían las comunidades vegetales posterior a los incendios, donde pueden definirse áreas con mayor o menor densidad de fuegos que impliquen, a su vez, un mayor stress en la vegetación, lo cual puede manifestarse en la estructura y fisionomía que va adoptando la vegetación en el tiempo.

Tabla 3. Superficie afectada por Incendios forestales en el periodo 1998-2006. Provincia de San Antonio.

\begin{tabular}{|l|c|c|c|c|c|}
\hline Comunes & $\begin{array}{c}\text { Superficie total } \\
(\mathrm{Ha})\end{array}$ & N.o incendios & Ha. quemadas & TMI (Ha) & DIN \\
\hline San Antonio & 40.500 & 1.292 & 5.935 & 4,6 & 0,354 \\
Cartagena & 24.600 & 440 & 3.117 & 7,1 & 0,199 \\
Santo Domingo & 53.600 & 100 & 2.755 & 27,6 & 0,021 \\
El Tabo & 9.900 & 95 & 1.940 & 20,4 & 0,107 \\
El Quisco & 5.100 & 224 & 845 & 3,8 & 0,488 \\
Algarrobo & 17.600 & 155 & 2.893 & 18,7 & 0,098 \\
\cline { 2 - 6 } Total & 151.300 & 2.306 & 17.485 & 7,6 & 0,169 \\
\hline
\end{tabular}

Fuente: CONAF, 1998-2006.

TMI: Tamaño Medio de Incendios (Ha).

DIN: Densidad de Incendios (N. ${ }^{\circ}$ Incendios $/ \mathrm{km}^{2} / \mathrm{año}$ )

Con respecto a la distribución anual que han experimentado los incendios vegetales en las comunas del área de estudio; la comuna del Quisco es la que se ha mantenido relativamente más constante en el periodo de 1998-2006, alcanzando en los años 2003 y 2005 un peak de ocurrencia de 31 y 33 episodios de incendios respectivamente. En tanto la comuna de Algarrobo presenta una mayor variación anual en 
los incendios, destacando para el año 1998 una frecuencia de 34 eventos. En cambio en la comuna del El Tabo, el número de incendios no ha superado los 16 episodios anuales, existiendo además ligeras variaciones entre 1998 y 2006 (figura 9).

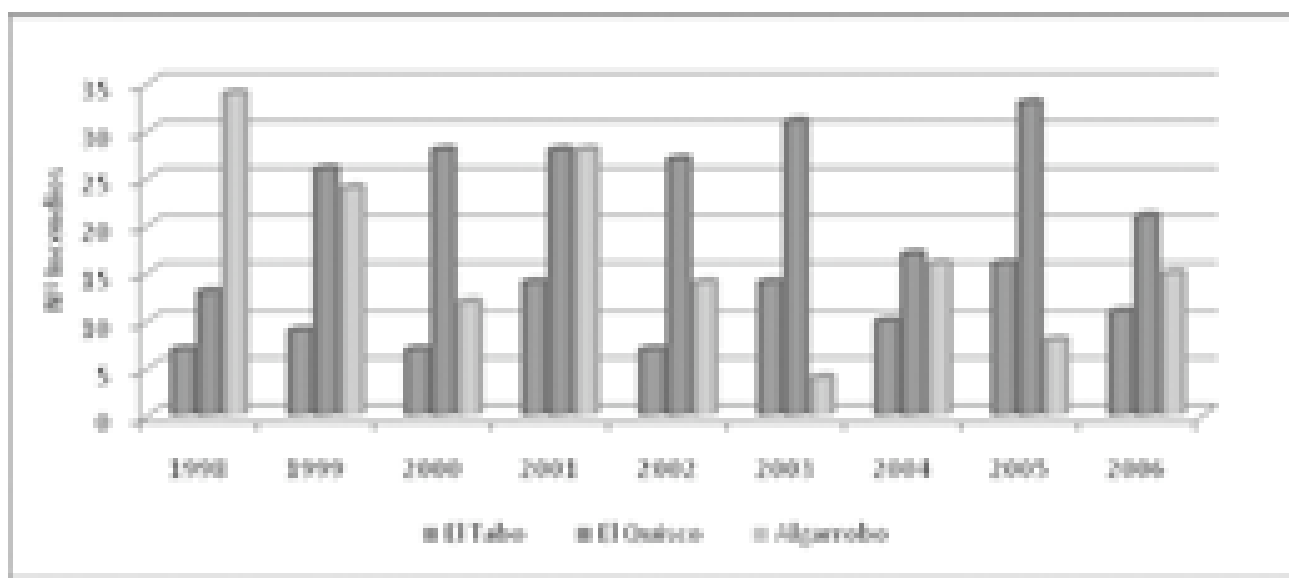

Figura 9. Distribución anual de los incendios forestales (1998-2006).

Acerca del tipo de vegetación que se vio afectada por los distintos incendios, en la comuna de Algarrobo es donde se observa una mayor proporción de alteración en la vegetación nativa, fundamentalmente sobre el matorral esclerófilo (1.368 ha), y en menor medida en pastizales y arbolado nativo. De la superficie quemada de la comuna de El Tabo, el matorral esclerófilo y pastizales son en proporción los más afectados por los incendios, destacándose además las plantaciones exóticas alteradas por los fuegos. En el caso de la comuna de El Quisco, los incendios se concentraron principalmente en las superficies de vegetación exótica y pastizales (figura 10).

Al espacializar los registros de incendios forestales en las comunas donde están situadas las microcuencas, queda en evidencia la ocurrencia de fuegos en los sectores litorales, coincidentemente próximos a los centros urbanos, destacándose una importante densidad de incendios hacia los sectores de El Quisco e Isla Negra, adyacentes a la Quebrada de Córdova. En esta área existe una frecuencia de fuegos que varían desde 10-15 hasta 20-30 episodios de incendios, todos generados entre los meses de Noviembre y Abril, concentrados principalmente en el mes de Enero (temporada estival). Cabe señalar para este sector, un evento de incendio en 1998 mayor a 100 ha, que afectó principalmente el Estero El Totoral (figura 11).

En cambio la situación de los fuegos hacia el área de la Quebrada de San Jerónimo, se presenta menos densa, ya que se han generado incendios en menor fre- 


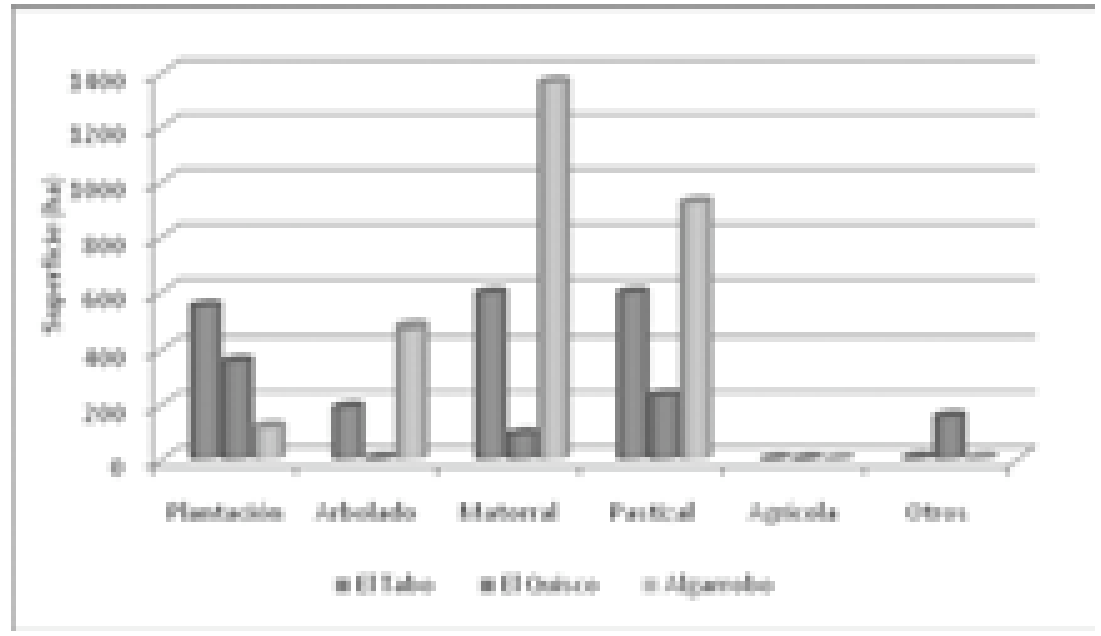

Figura 10. Tipo de vegetación afectada por incendios (1998-2006).

cuencia (1 a 5), donde únicamente se destaca para el año 2004, un importante episodio de fuego (sobre 100 ha), que afectó gran parte de las laderas del curso medio de esta microcuenca. Además en esta área los centros urbanos, favorablemente, no se encuentran contiguos a la quebrada al menos en el curso medio y superior, lo que disminuiría cierta amenaza de intervención constante sobre ésta; no así en el curso inferior, donde existe importante presión antrópica, que ha afectado principalmente el área de humedales, en la desembocadura del estero San Jerónimo (Humedal Los Patitos).

De acuerdo a estos antecedentes, se puede establecer que la Quebrada de Córdova entre el periodo 1998-2006, sería el sector con mayor incidencia en la ocurrencia de incendios; lugar donde se han concentrando hasta 15 eventos de fuegos que han afectado fundamentalmente el curso medio del estero. Esto hace suponer, que se generen importantes grados de alteración y degradación de las coberturas vegetales en esta microcuenca. Sin embargo esta situación no se manifiesta de modo estricto, al no observarse en la actualidad mayor testimonio de los incendios, como si sucede en la Quebrada de San Jerónimo, sobre todo en la degradación de la estructura y composición florística.

Esta diferencia de los efectos del fuego en las quebradas de estudio se debe principalmente a la intensidad, extensión y data de cada uno de los incendios, y fundamentalmente, por las características físicas que posee cada microcuenca (topografía, orientación, humedad); situación que ha sido favorable, en el caso de la Quebrada de Córdova, para la notable recuperación de los ecosistemas perturbados. 


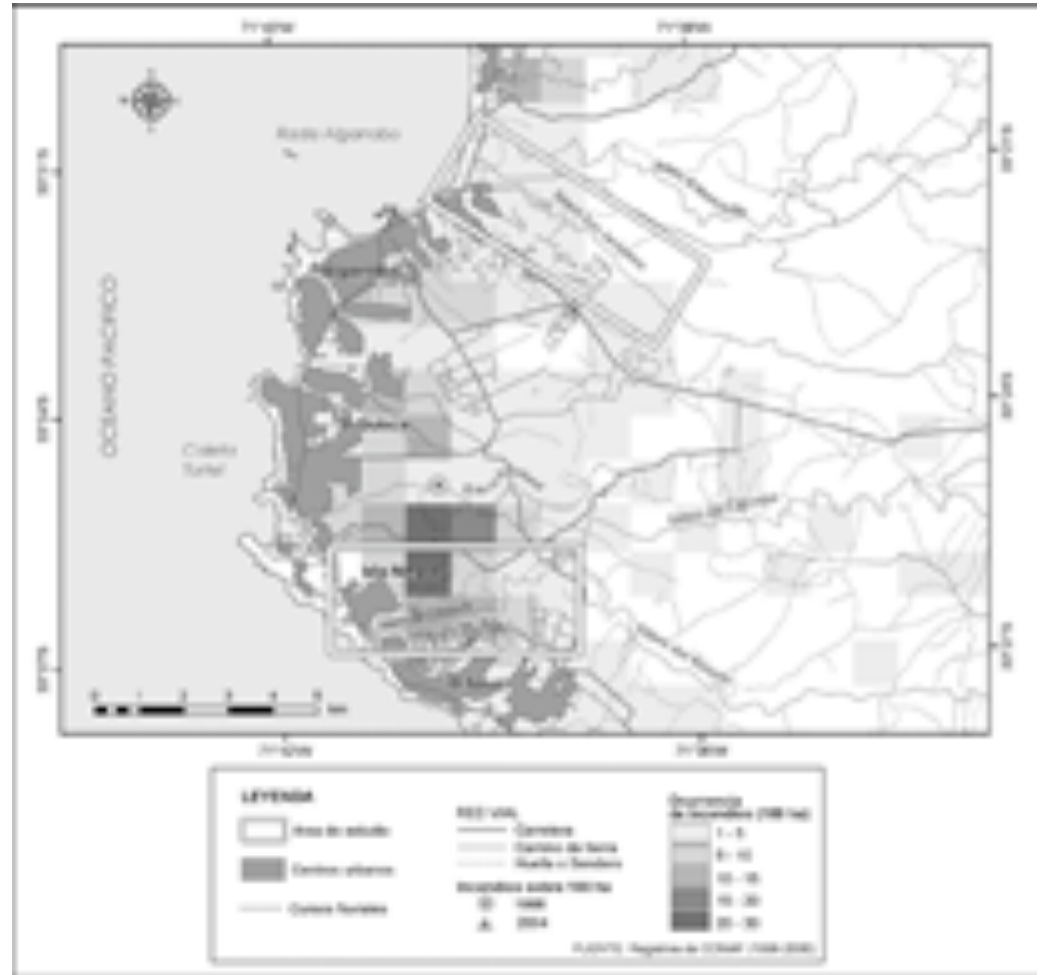

Figura 11. Ocurrencia de incendios (1998-2006) en las quebradas en el área de estudio.

Con respecto a la dinámica de regeneración postfuego, en la Quebrada de San Jerónimo la vegetación ha adoptado una estructura de matorral degradado, con una muy alta cobertura de especies invasoras o de aquellas especies nativas que no conformaban inicialmente un dominio dentro de la composición vegetal. Ejemplo de ello es la propagación que ha experimentado Chusquea cumingii luego de los incendios, al igual que Retanilla trinervia, pero en menor magnitud; teniendo una mayor capacidad de colonización y regeneración que otras especies nativas, generando actualmente un predominio importante dentro de las coberturas vegetales intervenidas (figura 12).

En tanto en la quebrada de Córdova, los efectos del fuego no se han mostrado con una clara evidencia, ya que se ha mantenido aparentemente cierta estructura vegetal en las áreas intervenidas. No obstante existen sectores en el curso medio de la quebrada, que se encuentran alterados por un importante incendio de hace 14 años atrás, ya fuera del periodo de registros analizados; donde la estructura de la vegeta- 


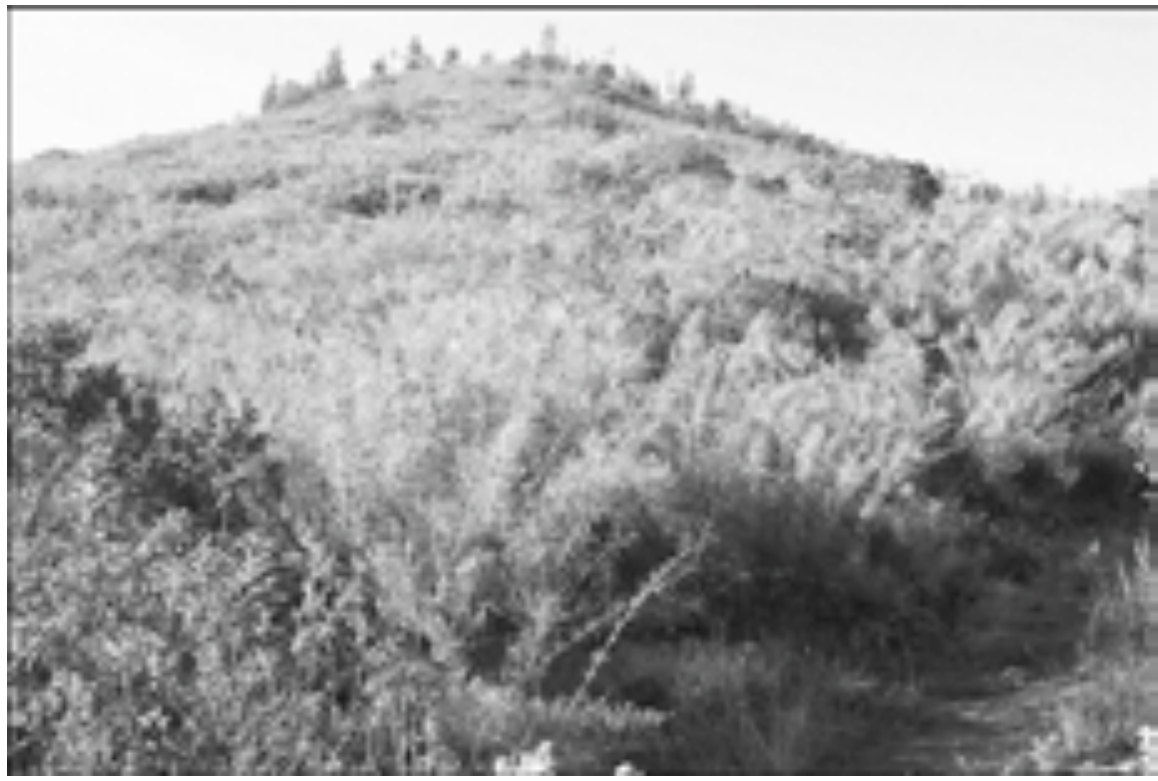

Figura 12. Dominio de agrupaciones de Chusquea cumingii en áreas alteradas por los fuegos. Quebrada de San Jerónimo.

ción ha presentado algunos claros, que ha permitido la propagación de especies como Rubus ulmifolius y Chusquea cumingii, implicando necesariamente cambios en la composición florística del bosque esclerófilo húmedo e higrófito (figura 13).

Es importante considerar además otros factores que puedan tener implicancia en la degradación de la vegetación y del ecosistema en general, como es el caso de los procesos erosivos. De acuerdo a esto, en ambas quebradas se han evidenciado importantes procesos de erosión con distintos grados de influencia en la degradación de los ecosistemas de quebradas.

La erosión en las microcuencas costeras se ha generado por distintas causas, reconociéndose como los principales factores: las condiciones climáticas; relieve o topografía; naturaleza y propiedades del suelo; y factor antrópico.

Las condiciones climáticas como factor de erosión estarían asociadas principalmente al agente hídrico (precipitaciones y escorrentía superficial), que es probablemente el factor erosivo más importante, del cual depende la intensidad y duración de las lluvias. No obstante su incidencia sobre los suelos también será relativa a otros factores, como el topográfico (pendientes) y propiedades del suelo (infiltración). 


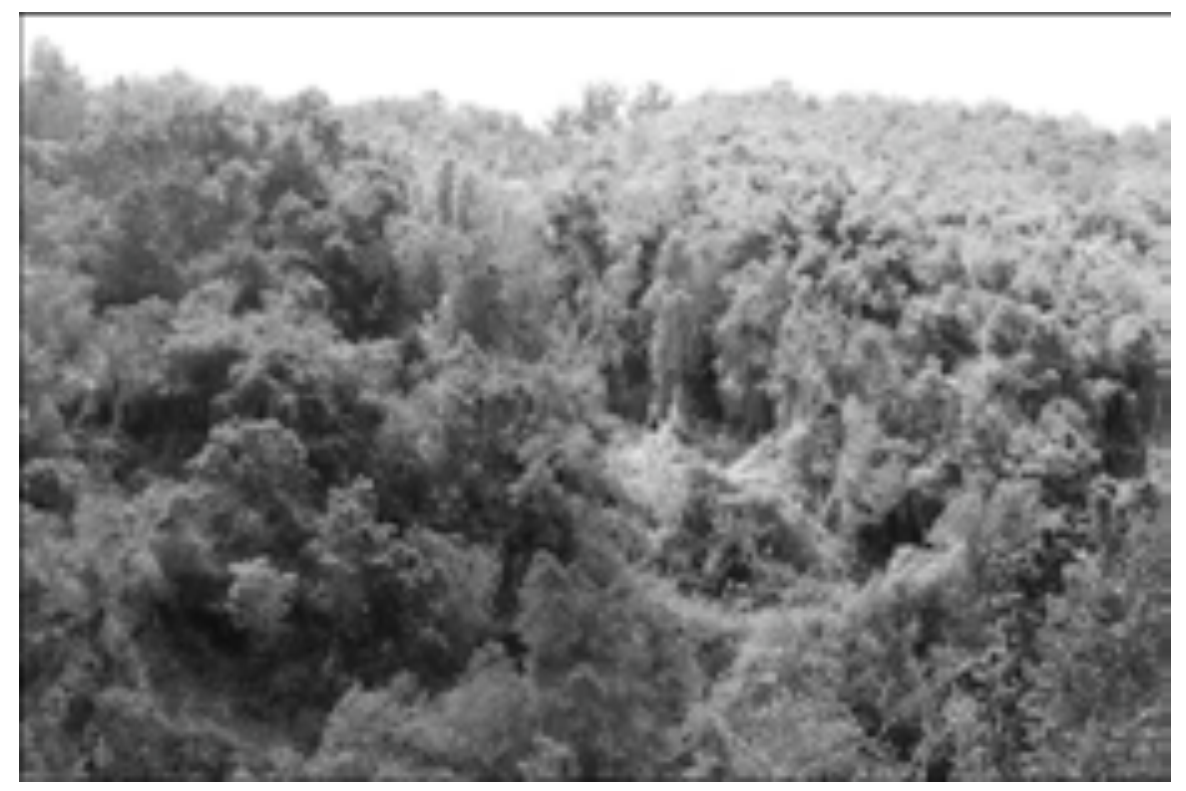

Figura 13. Estructura vegetal postfuegos. Ladera de orientación sur. Quebrada de Córdova.

Para el caso de las quebradas, las características de su clima mediterráneo, con grandes contrastes en la distribución anual de las precipitaciones, generan las condiciones propicias para favorecer la acción de la lluvia en los procesos erosivos. De acuerdo a ello, en los meses de verano la vegetación comienza a disminuir, dejando los suelos expuestos para que con las primeras lluvias invernales, que suelen ser concentradas y torrenciales, se remueva primero la capa superficial (erosión laminar) y posteriormente, por concentración de la energía, la precipitación genere disección del terreno (Castro y Vicuña, 1990).

Según los índices de intensidad de la lluvia y grado de concentración estacional, queda en evidencia para el área litoral mediterránea de la provincia de San Antonio, la agresividad de la lluvia como agente erosivo, teniendo su punto crítico en el mes de Junio (Castro y Vicuña, 1990).

Esta situación se puede observar en ambas microcuencas, principalmente en la quebrada de Córdova, donde los procesos erosivos por agentes hídricos han ocasionado importante erosión, inicialmente de forma laminar, para que paulatinamente se vaya generando una erosión de surcos y de zanjas o cárcavas (figuras 14 y 15). 


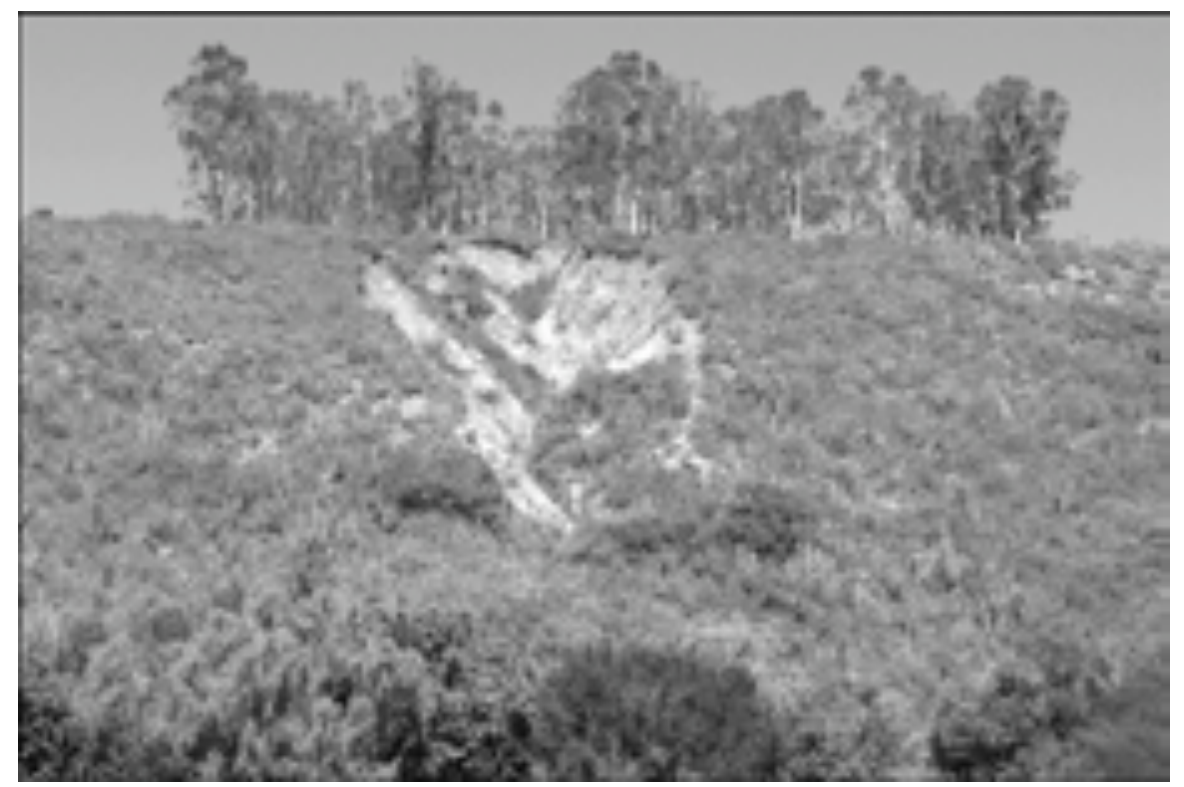

Figura 14. Cárcavas en laderas de altas pendientes, con protección arbórea (Eucalyptus globulus) en sus cabeceras. Quebrada de San Jerónimo.

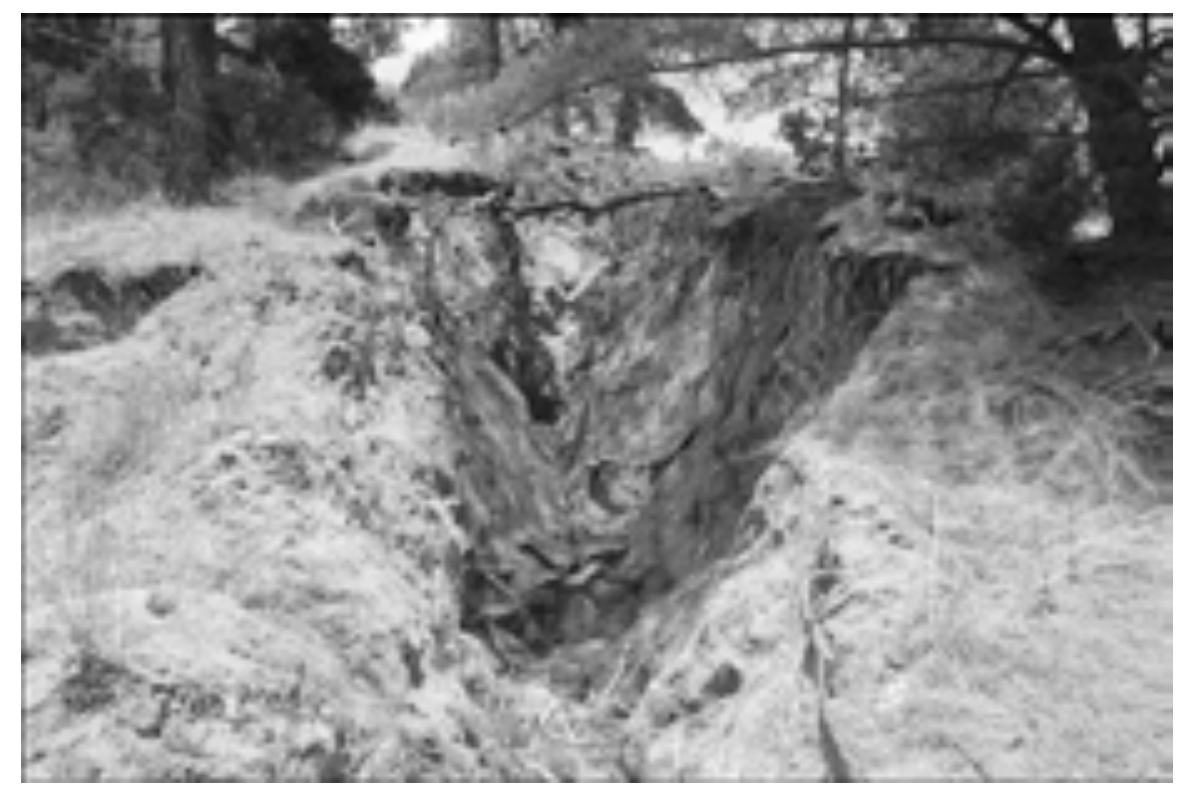

Figura 15. Erosión en zanja (cárcava) en un sector de ladera de la Quebrada de Córodova. 
El relieve o topografía es otro de los factores preponderantes que induce una mayor erosividad, sobre todo en los sectores que poseen mayor pendiente, como es el caso característico de las quebradas en estudio, las cuales presentan por lo general pendientes sobre el 25\%. Por lo tanto los relieves ondulados o con rupturas de pendiente posibilitarían el comienzo de la erosión, de tal modo que el tamaño y la cantidad de material que el agua puede arrastrar o llevar en suspensión, dependen de la velocidad con que ésta fluye, la cual, a su vez, es una resultante de la longitud y el grado de pendiente del terreno (Suárez de Castro, 1979).

Tanto en la Quebrada de San Jerónimo como en la de Córdova, se reconoce lo importante que pueda resultar ser el factor topográfico en la potencialidad de erosión, sobre todo en sectores con escasa cobertura vegetal o de estructura disminuida (matorral abierto), situadas generalmente en laderas de solana o de exposición norte (figuras 16 y 17).

También es común observar en las microcuencas procesos de erosión en los sustratos rocosos, los cuales quedan al descubierto en varios sectores de altas pendientes, cuyos factores ambientales asociados a la dinámica de ladera, generaría fuertes procesos de meteorización, desprendiéndose los materiales, que por gravedad, se deslizan hacia los sectores inferiores de las quebradas. Este proceso ha involucrado

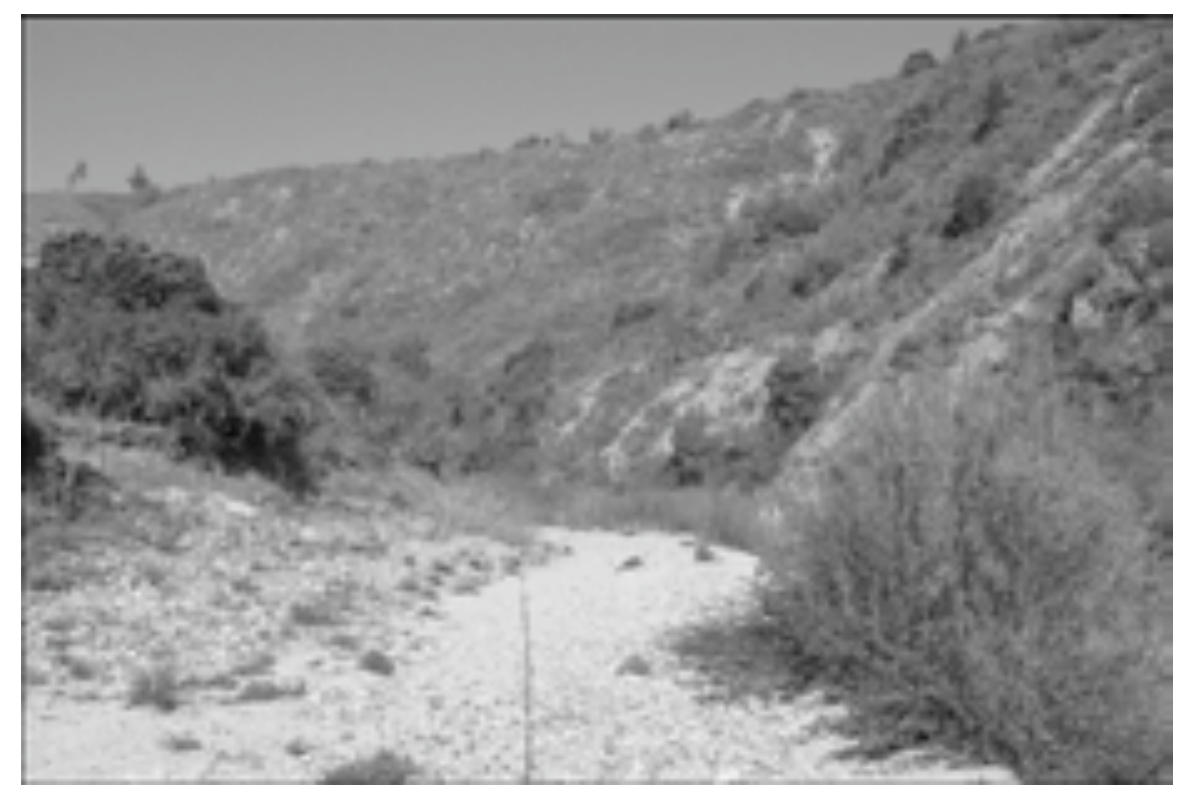

Figura 16. Laderas con fuertes pendientes con evidencia de erosión. Quebrada de San Jerónimo. 


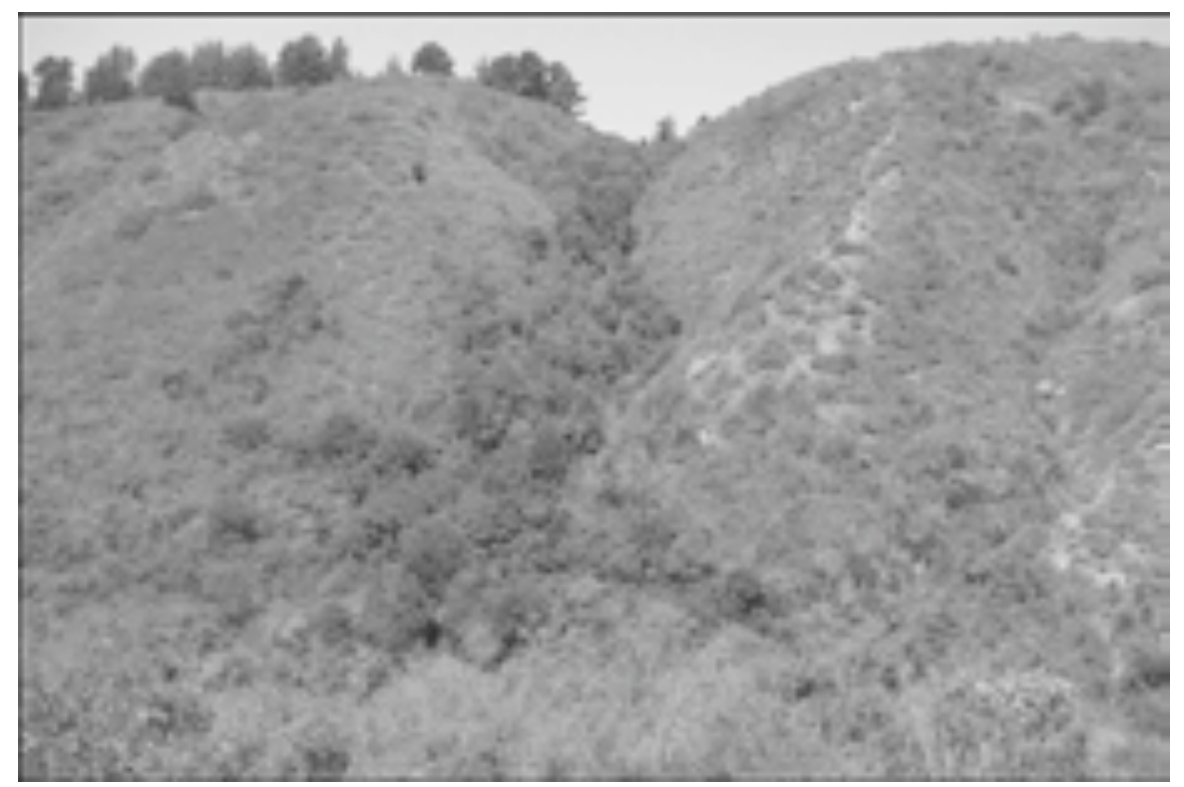

Figura 17. Las fuertes pendientes han implicado la erosión de laderas, adyacente a un enclave de bosque relicto de olivillo (Aextoxicon punctatum) y canelo (Drimys winteri).

Quebrada de Córdova.

en algunos sectores de la Quebrada de Córdova el embancamiento de su estero, como consecuencia del arrastre de material por los distintos tipos de erosión en las áreas de laderas.

La naturaleza y propiedades del suelo también son otros de los aspectos a considerar que pueda favorecer los procesos de erosión, debido a que existen condiciones físicas y químicas (y biológicas) de los suelos, que otorgan mayor o menor resistencia a los agentes erosivos (erodabilidad). En el caso de los suelos de las quebradas, éstos se constituyen principalmente por "maicillo", producto de la alteración de rocas cristalinas; suelos definidos por CIREN (1997) con clase textural superficial franco arenosa. Si bien éstos poseen un buen drenaje, hay varios sectores, principalmente de la Quebrada de Córdova, donde la capacidad de infiltración se ha visto sobrepasada, teniendo como consecuencia la generación de escorrentía superficial, y por ende, el desencadenamiento de procesos erosivos.

Por otra parte, las distintas actividades antrópicas también han implicado diversos impactos al medio natural, que directa e indirectamente, han originado procesos de erosión. Entre los efectos negativos generados por el hombre se encuentra principal- 
mente la intervención sobre la vegetación nativa, fundamentalmente a través de los incendios vegetales, explotación de bosques (leña, madera) y por la acción del ganado (ramoneo y pisoteo).

La importancia de la vegetación se basa en la protección que le otorgan a los suelos, de tal modo de poder disminuir mediante el follaje y hojarasca, el impacto que tiene la lluvia sobre el terreno. También permite la estabilización de laderas, principalmente por el enraizamiento de las especies vegetales, donde el agua que escurre pierde velocidad, arrastrando menos material particulado, sobre todo en áreas de pendientes, generando además una mayor infiltración y retención de las aguas, disminuyendo de este modo la potencialidad de los agentes erosivos (Espinoza et al., 1998).

En las quebradas de San Jerónimo y de Córdova la presión antrópica se ha dado de distinta forma y magnitud, siendo precisamente los fuegos, los que han afectado en mayor medida a la vegetación, en términos de degradación de su composición florística y estructura; lo que facilitaría potencialmente la ocurrencia de fenómenos erosivos en las microcuencas (figuras 18 y 19 ).

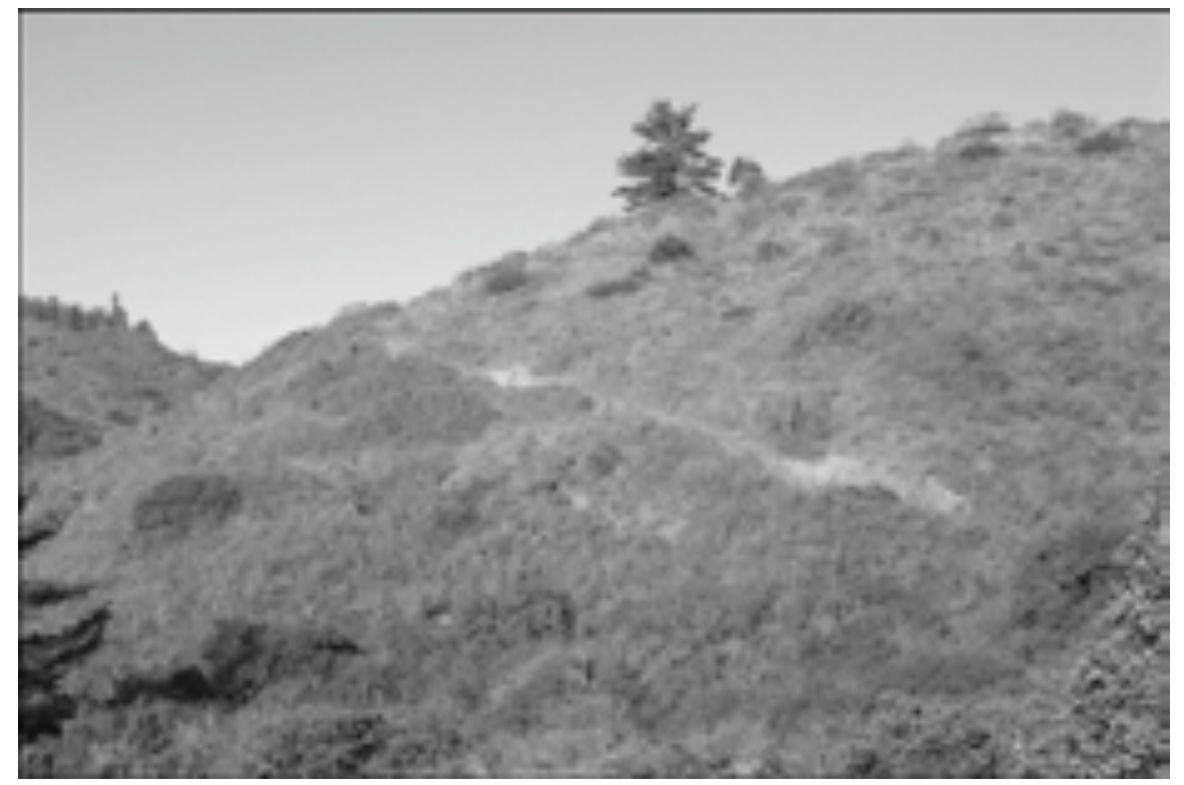

Figura 18. Los fuegos de la Quebrada de San Jerónimo han implicado un deterioro progresivo de la estructura vegetal, generando pérdida de cobertura para la protección de laderas. 


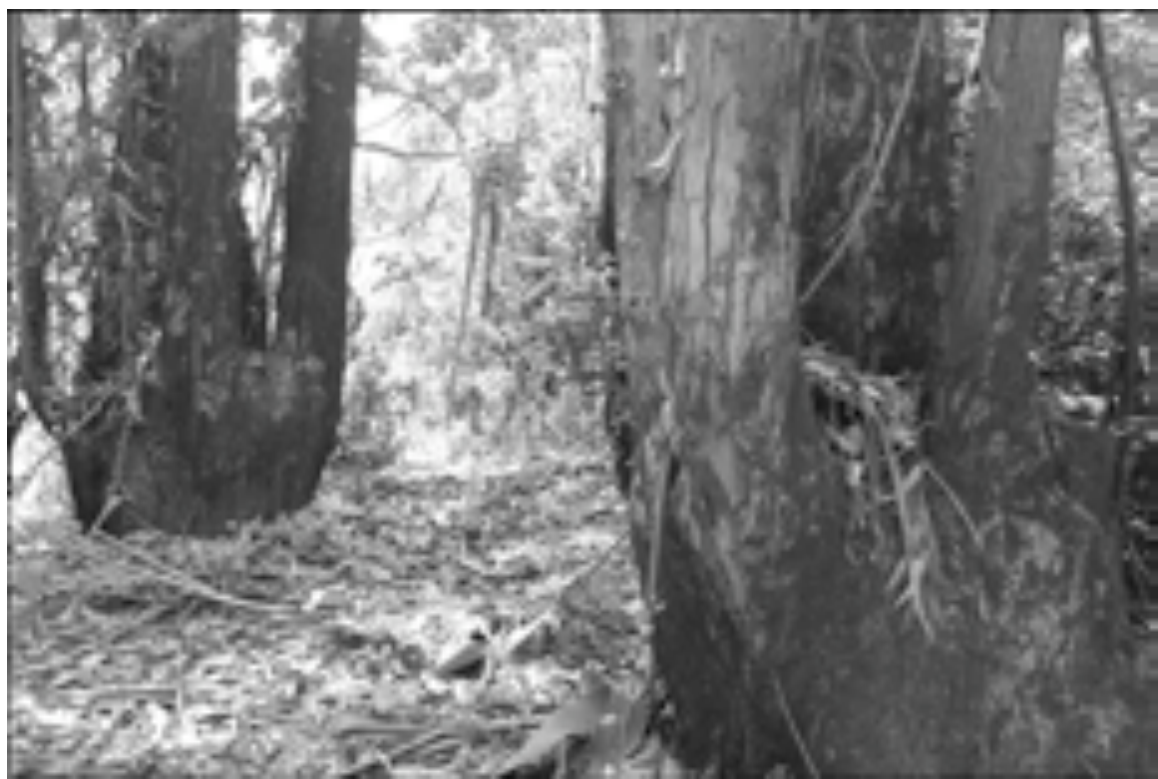

Figura 19. Evidencias de incendios en el sotobosque de una plantación exótica (Eucalyptus globulus) próxima al curso fluvial, afectando también la vegetación nativa contigua.

Quebrada de Córdova.

Otra de las alteraciones asociadas a la acción humana tiene relación con la actividad turística, que dada la atracción que poseen estos sectores como áreas verdes y de recreación; se produce en épocas estivales una gran carga de visitantes, los cuales generan diversas perturbaciones, ya sea en la vegetación (quemas, corte de ramaje), como en el suelo (pisoteo, compactación), acelerando la erosión, principalmente en los sectores de transito (senderos habilitados y no habilitados).

\subsection{Antecedentes sobre restauración en las microcuencas}

Se ha señalado que ambas quebradas poseen testimonios de degradación, siendo los incendios vegetales y la erosión los agentes más perturbadores de estos ecosistemas.

En general la degradación se ha manifestado como una consecuencia postfuegos de la vegetación, particularmente en la microcuenca de San Jerónimo, cuyo último incendio de relativa consideración, en cuanto a magnitud y extensión, se generó en 
el año 2004; a diferencia de la Quebrada de Córdova, donde el último fuego importante ocurrió hace 14 años atrás.

Los incendios forestales, debido particularmente al cálido, seco y largo verano del clima mediterráneo de Chile Central, son actualmente el riesgo más regular; cuya principal consecuencia, además de eliminar especies, es generar procesos erosivos y acelerar los ya existentes.

La restauración de áreas forestales incendiadas debe preocuparse, aparte de la cubierta vegetal degradada, de otras acciones complementarias, como las obras de hidrología necesarias para la consolidación de cauces y laderas; contención de sedimentos de acotamiento del pastoreo; la saca de residuos; apertura de vías de acceso, etc. (Harris y Van Diggelen, 2006).

En estas microcuencas se debe intentar realizar tratamientos de ayuda a la regeneración natural. Si las especies presentes en las quebradas tienen capacidad de regeneración postfuego (germinadoras o rebrotadoras), que garantizan la regeneración de la cubierta vegetal en las áreas incendiadas; las acciones silvícolas a efectuar deben tender a facilitar y promover lo mismo. Según Navarro et al. (2000), este tipo de tratamiento puede realizarse en dos momentos diferentes:

a) Previo a la regeneración: La actuación fundamental será extraer la madera quemada, tanto de las especies germinadoras como rebrotadoras, para eliminar el riesgo de plagas y favorecer el rebrote con más vigor. Sin embargo es importante mantener los tocones y estructuras vegetales subterráneas, por cuanto, según Fernández et al. (2010), a partir de su rebrote y la colonización de especies pioneras, a través de semillas, se iniciará la sucesión ecológica. Esto debería considerarse para la microcuenca de San Jerónimo, donde existen aun tocones quemados; que favorecerían el crecimiento germinativo, y si se lleva a cabo la exclusión de ganado, beneficiaría al mismo tiempo ambos tipos de germinación.

Hay que tener muy presente en la aplicación de este tratamiento en las quebradas, que el suelo luego de los eventos de incendios, adoptan condiciones de alta fragilidad, por lo que las acciones que se realicen no deben aumentar la erosión. Otra instancia de acción, que suele ser necesaria, es recuperar o restaurar los sectores alterados con motivo de labores de extinción, los cuales habría que llevar a cabo en la microcuenca de San Jerónimo (corta fuegos, pistas, líneas de defensa).

b) Posterior a la regeneración: Una vez recuperada la cubierta vegetal, deben realizarse tratamientos silvícolas de selección de rebrotes, particularmente en los espacios abiertos. En las masas frondosas mediterráneas, las estrategias reproductoras después de los incendios están dominadas por la reproducción vegetativa, ya que en su generalidad, todas las especies arbóreas y arbustivas presentes, cuentan con meca- 
nismos de resistencia al fuego. Además se debe excluir el ganado y potenciales herbívoros, para así evitar el ramoneo de la regeneración. Esto es muy necesario en la microcuenca de San Jerónimo, en la cual el ganado transita con cierta regularidad, contribuyendo por lo demás a la erosión; situación que ocurre muy poco en la Quebrada de Córdova.

La germinación por semillas o a partir de tocones, en forma individual o complementada, mejora la resiliencia del ecosistema, acelerando el proceso de restauración ecológica, evitando además gastos inútiles de tiempo y dinero. Por ello entonces sería necesario efectuar un constante monitoreo en los ecosistemas de ambas microcuencas o quebradas.

Una vez realizadas estas acciones, y recuperada la vegetación, se debe procurar proteger los ecosistemas, generando delimitaciones (cercados), también realizar senderos y además etiquetar las plantas representativas, para otorgar de este modo a la comunidad una educación ambiental. Como en estas pequeñas cuencas existe una importante invasión de Rubus ulmifolius, siendo una especie agresiva; ésta debe ser extraída.

Resulta evidente la relevancia botánica de la biota de estas microcuencas, y muy en particular para la Quebrada de Córdova, que representa una poderosa herramienta educativa, considerando su accesibilidad y cercanía a los grandes centros urbanos y turísticos de la zona mediterránea de Chile.

La numerosa y diversificada flora y fauna (sobre todo de aves) de la Quebrada de Córdova, permite además conocer nociones de taxonomía, de ecología, de biogeografía y evolución, como también de recreación; observando contrastes vegetacionales que conforman un paisaje armónico, que atrae espontáneamente a los aficionados a la naturaleza (Villagrán et al., 2003).

Con respecto a la erosión, se ha reconocido que los factores climáticos (lluvias) y topográficos (pendientes), le otorgarían a ambas quebradas características propias de ambientes frágiles, lo que determina cierta inestabilidad en la dinámica geomorfológica y de suelos. Situación que se acrecienta aun más con las intervenciones antrópicas, fundamentalmente con los incendios vegetales; teniendo como consecuencia que los suelos tengan entonces una mayor susceptibilidad de ser erosionados.

Teniendo estos antecedentes, sería importante poder definir algunas de las medidas prioritarias de restauración o conservación de suelos para estas microcuencas, que necesariamente deberían tener implicancia sobre la vegetación. En el caso de la Quebrada de San Jerónimo, y dado los procesos de degradación que se han podido observar, que están asociados fundamentalmente a la erosión de laderas en sus cabeceras; a modo de restauración, se hace necesaria la protección de éstas a través de 
especies vegetales, para disminuir la probabilidad de ocurrencia de procesos erosivos. Sin embargo la idea es efectuar esta protección con especies nativas arbóreas o arbustivas del bosque esclerófilo (Quillaja saponaria, Lithraea caustica, Colliguaja odorifera, Chusquea cumingii) para no abandonar el objetivo de restauración ecosistémica de estas áreas; y prescindir, si no existen procesos erosivos urgentes, de la plantación de Eucalyptus globulus, que por lo demás es una especie de alta combustibilidad, por lo que también se disminuiría los riesgos de incendios.

En tanto en la Quebrada de Córdova, donde se han reconocido importantes procesos de degradación erosiva, en muchos casos en estados avanzados, con presencia de cárcavas; entre las medidas principales y más urgentes que se deban aplicar en esta microcuenca, se encuentran: 1) Regulación de los flujos hídricos de la escorrentía superficial, la cual debería realizarse a través de la implementación de canales de desviación o canales transversales; obra que resulta sencilla de ejecutar, teniendo bajo costo, siendo recomendada para caminos operacionales y rurales de pendientes escarpadas, como es el caso de la quebrada. 2) Contención y estabilización de taludes, mediante la construcción de empalizadas, las cuales deben ser capaz de frenar o controlar la aceleración erosiva en sectores de pendiente.

\section{Conclusiones}

Se demuestra en gran parte la riqueza florística de dos microcuencas que se ubican en la costa mediterránea de Chile Central.

De acuerdo al microclima y a las características de relieve existentes en las quebradas, se encuentra una importante variedad florística, destacando en la microcuenca de Córdova la presencia de tres especies arbóreas endémicas, además de una cierta heterogeneidad de hábitats y de comunidades, como consecuencia de contrastes ecológicos generados, en gran parte, por su notable recuperación después de los fuegos.

La Quebrada de San Jerónimo, con mayor evidencia de intervención, posee sólo características mésicas, con presencia de matorral y bosque esclerófilo. En cambio la microcuenca de Córdova, por la existencia de un microclima muy húmedo, tiene condiciones mésicas e higrófitas que permiten el crecimiento de plantas húmedas, incluyendo tres especies endémicas y un árbol higrófito relictual.

Sin embargo los incendios vegetales, la erosión y en algunos casos el pastoreo, no han sido ajenos en dificultar la sucesión de estas comunidades, especialmente en la Quebrada de San Jerónimo, donde se ha observado una muy lenta regeneración de la cubierta vegetal. 
La presencia de un permanente microclima que permite una mayor diversidad y cobertura vegetal, otorgan un gran valor ecológico a la microcuenca de Córdova. El interés biogeográfico en ella reside en sus relaciones florísticas con la vegetación relictual de la costa de Chile, tanto con enclaves de la zona mediterránea como de la zona sur. La variedad de aves también es interesante, encontrándose lugares de nidificación.

Organismos públicos y privados de las comunas de Algarrobo, El Quisco y El Tabo (Provincia de San Antonio), además de organizaciones ecologistas, realizan una importante gestión para que el Estado chileno declare estas quebradas como Monumentos Naturales, especialmente la Quebrada de Córdova, considerada como un Sitio Prioritario de Conservación; definición que es parte de la Estrategia Nacional para la Conservación de la Biodiversidad en Chile.

\section{Agradecimientos}

Proyecto DICYT-USACH № 91212 QP

\section{Referencias}

Araya-Vergara, J. (2000) Desarrollo de superficies de aplanamiento disectadas sobre coast range en la Región del Maule, Chile Central. Investigaciones Geográficas, 34.

Braun-Blanquet, J. (1979) Fitosociologia: Bases para el estudio de las comunidades vegetales. Madrid, Ediciones Blume,

Castillo, M.; Julio, G. y Garfias, R. (2010) Análisis estadístico de incendios forestales en el periodo 1976-2006 en la región Mediterránea. Estudio realizado como parte del Proyecto FONDECYT № 1095048. Documento inédito. 70 p.

Castro, C. y P. Vicuña (1990) Caracterización de la erosión lineal en planicies costeras de Chile Central. Revista de Geografía Norte Grande, 17, 37-45.

CIREN (1997) Descripciones de suelos y materiales y símbolos. Estudio agrológico de la V Región. Publicación CIREN № 116.
Espinoza, G.; Fuentes, E. y Molina, J.D. (1988) La erosión: fenómenos naturales y acción del hombre. En: Ecología del Paisaje en Chile Central, 53-64, Fuentes, E. \& S. Prenafeta Eds. Universidad Católica de Chile.

Fernández, I; Morales, N.; Olivares, L.; Salvatierra, J.; Gómez, M. y Montenegro, G. (2010) Restauración ecológica para ecosistemas nativos afectados por incendios forestales. Santiago de Chile, PUC.

Gajardo, R. (1994) Las formaciones vegetales de Chile. Santiago de Chile, CONAF.

Galarce, S. y Penrroz , A. (2010) Estudio de la degradación de la Quebrada de San Jerónimo por los incendios vegetales. Memoria Título Ing. Geógrafo, Universidad de Santiago de Chile.

Hajek, E.R., y Di Castri, F. (1975) Bioclimatografía de Chile. Dirección de 
Investigación. Vice-Rectoría Académica de la Universidad Católica de Chile. Santiago.

Harris, J.A. y Van Diggelen, R. (2006) Ecological restoration as a project for global society. En: Van Andel, J. y Aronson, J. (eds.): Restoration Ecology, the new frontier, 3-15, Blackwell, London.

Kummerow, J. (1966) Aporte al conocimiento de las condiciones climáticas del bosque de Fray Jorge. Bol. Técnico Facultad Agronomia, 24, 21-28. Universidad de Chile.

Looser, G. (1935) Argumentos botánicos a favor de un cambio de clima en Chile Central en tiempos geológicos recientes. Revista Universitaria, 20(6-7), 843-857.

Muñoz, C. y Pisano, E. (1947) Estudio de la vegetación y flora de los Parques nacionales de Fray Jorge y Talinay. Agricultura Técnica, 7(2), 71-190.

Muñoz-Schick, M.; Núñez, M.H. y Yáñez, J. (eds., 1996) Libro Rojo de los Sitios Prioritarios para la Conservación de la Diversidad Biológica de Chile. CONAF.

Navarro, R.; Fernández, P. y Escuin, S. (2000) Metodología para la evaluación de daños y propuestas de actuaciones para restauración ecológica en áreas incendiadas. Universidad de Córdoba (España)

Quintanilla, V. (1983) Biogeografía de Chile. Santiago, Eds. Inst. Geográfico Militar de Chile.

Sanhueza, P. (2001) Fire situation in Chile. In Galdames, J.G y Mutch, R.W. (eds.) Global forest fire assessment 1990-2000. Roma, Forest Resources Assessment. FAO.
Schmithusen, J. (1956) Die raumliche Ordnung der dhilenischen Vegetation. Bonner Geographische Abhandlungen, 17, 1-89.

Skottsberg, C. (1948) Apuntes sobre la flora y vegetación de Fray Jorge (Coquimbo, Chile). Acta Gotoburgensis,18, 91-194.

Suárez de Castro, F. (1979) Conservación de suelos: un estudio internacional. Instituto Interamericano de Ciencias Agrícolas (IICA) Costa Rica.

Troncoso A.; Villagrán, C. y Muñoz, M. (1980) Una nueva hipótesis acerca del origen y edad de bosque Fray Jorge (Coquimbo, Chile). Bol. Museo Historia Natural de Chile, 37, 117-152

Villagrán, C. y Armesto, J. (1980) Relaciones florísticas entre las comunidades relictuales del Norte Chico y la zona Central con el bosque del Sur de Chile. Boletín Museo Nacional de Historia Natural de Chile, 37, 87-101

Villagrán, C.; Riveros, M.; Villaseñor, R. y Muñoz, M. (1980) Estructura florística y fisionómica de la vegetación boscosa de la quebrada de Córdoba (El Tabo) Chile Central. Anales del Museo de Historia Natural, 13, 71-91.

Villagrán, C.; Medina, C. y Armesto, J. (2003) Antecedentes biológicos que fundamentan la conservación de la quebrada de Córdova (El Tabo, Chile Central) como área protegida del estado. Facultad de Ciencias. Universidad de Chile. 15 p. 